
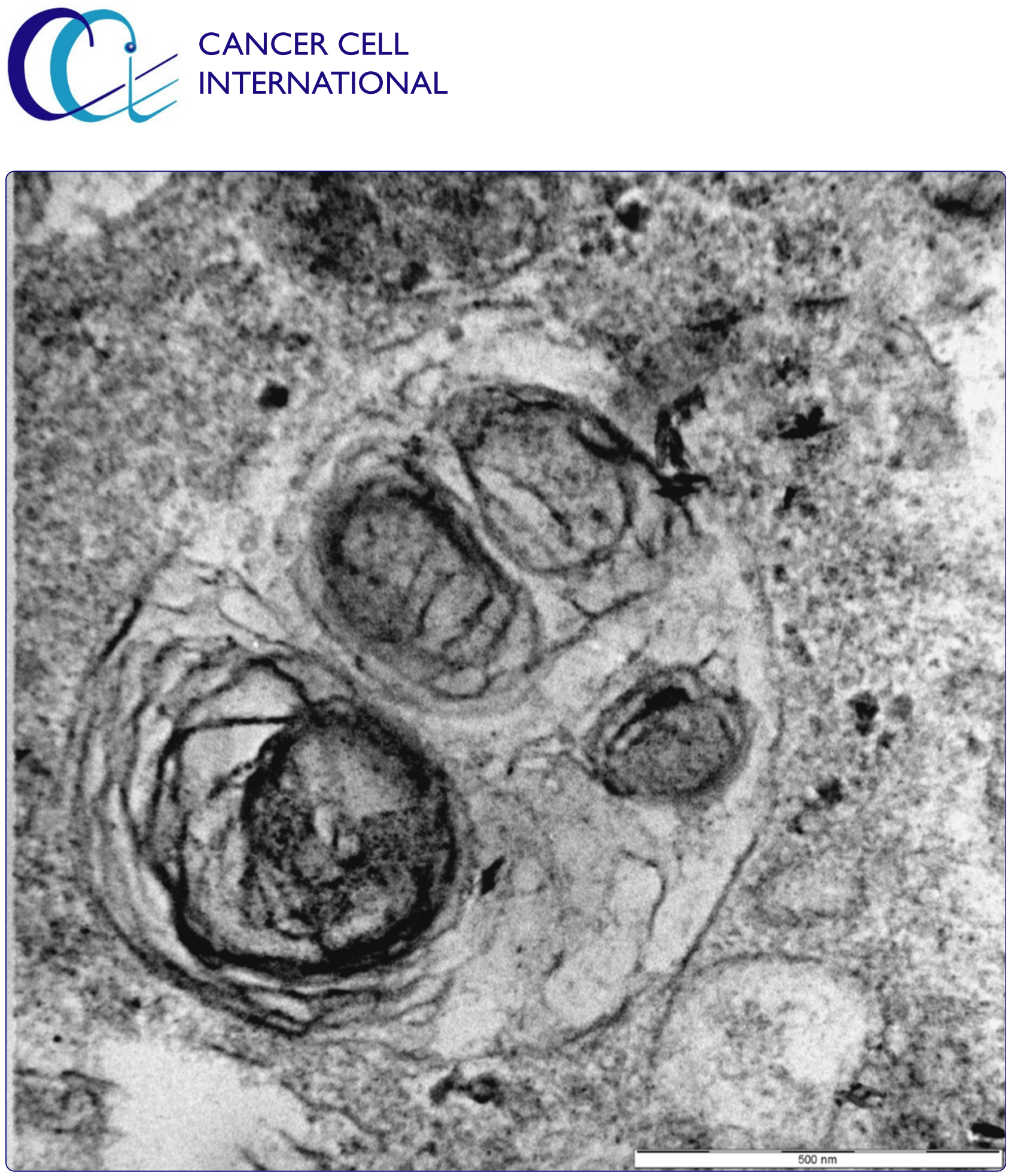

Molecular crosstalk between apoptosis and autophagy induced by a novel 2-methoxyestradiol analogue in cervical adenocarcinoma cells

Theron et al. 


\title{
Molecular crosstalk between apoptosis and autophagy induced by a novel 2-methoxyestradiol analogue in cervical adenocarcinoma cells
}

\author{
Anne Theron $^{1 *}$, Elsie M Nolte ${ }^{1}$, Laurence Lafanechère ${ }^{2}$ and Annie M Joubert ${ }^{1}$
}

\begin{abstract}
Background: 2-Methoxyestradiol has been shown to induce both autophagy and apoptosis in various carcinogenic cell lines. Although a promising anti-cancer agent, it has poor bioavailability and rapid in vivo metabolism which decreases its efficiency. In order to improve 2-methoxyestradiol's anti-proliferative properties, a novel 2methoxyestradiol analogue, 2-ethyl-3-O-sulphamoyl-estra-1,3,5 (10)16-tetraene (ESE-16), was previously in silicodesigned in our laboratory. This study investigated ESE-16 for its anti-proliferative potential on a cervical adenocarcinoma cell (HeLa) cell line. Additionally, the possible intracellular crosstalk mechanisms between the two types of cell death were investigated.

Methods and results: HeLa cells exposed to $0.5 \mu \mathrm{M}$ ESE-16 for 24 hours showed morphological evidence of both apoptotic and autophagic death pathways as assessed by polarization-optical transmitted light differential interference contrast microscopy, fluorescent microscopy and transmission electron microscopy. Flow cytometric cyclin B1 quantification revealed induction of programmed cell death after halting cell cycle progression in metaphase. Confocal microscopy demonstrated that ESE-16 caused microtubule fragmentation. Flow cytometric analysis of cell cycle progression and phosphatidylserine flip determination confirmed induction of apoptosis. Moreover, an increase in aggresome formation and microtubule-associated protein light chain, LC3, was demonstrated indicative of autophagy. Both caspase 8 and 3 were upregulated in a spectrophotometric analysis, indicating the involvement of the extrinsic pathway of apoptotic induction.

Conclusions: We conclude that the novel in silico-designed compound, ESE-16, exerts its anti-proliferative effect on the tumorigenic human epithelial cervical (HeLa) cells by sequentially targeting microtubule integrity, resulting in a metaphase block, causing induction of both autophagic and apoptotic cell death via a crosstalk mechanism that involves the extrinsic pathway. Future investigations will expand on signal transduction pathways involved in both apoptosis and autophagy for assessment of ESE-16 effects on microtubule dynamic instability parameters.
\end{abstract}

Keywords: 2-methoxyestradiol, ESE-16, Analogue, Apoptosis, Autophagy, Caspase, Crosstalk, Mitotic block, Microtubules, 2-ethyl-3-O-sulphamoyl-estra-1,3,5(10)16-tetraene

\section{Background}

Registered as Panzem ${ }^{\circ}$ by Entremed, Inc (Rockville, MD), 2-methoxyestradiol (2-ME) (Figure 1a), an endogenous metabolite of $17 \beta$-estradiol resulting from sequential hepatic hydroxylation and methylation by cytochrome $\mathrm{P} 450$ enzymes and catechol-O-methyltransferase respectively, has undergone phase II clinical trials [1-3]. 2-ME induces

\footnotetext{
* Correspondence: joji.theron@up.ac.za

'Department of Physiology, Faculty of Health Sciences, University of Pretoria, Private Bag X323, Arcadia, 0007 Gauteng, Pretoria, South Africa

Full list of author information is available at the end of the article
}

apoptosis in endothelial cells, as well as cancer cells by the intrinsic and extrinsic pathways by both caspase dependent and -independent pathways [2,4-6]. Not only has 2-ME proven effective in primary treatment settings, but it has also demonstrated the capability to sensitize therapy-resistant neoplastic cell types to conventional anti-cancer treatments including radiation therapy $[7,8]$. For this reason 2-ME seemed to be a promising anti-cancer agent, especially in the light of findings that non-neoplastic cell lines were less affected than cancer cell lines by exposure to the compound [9].

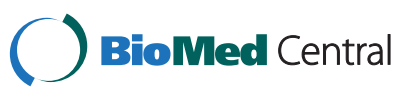



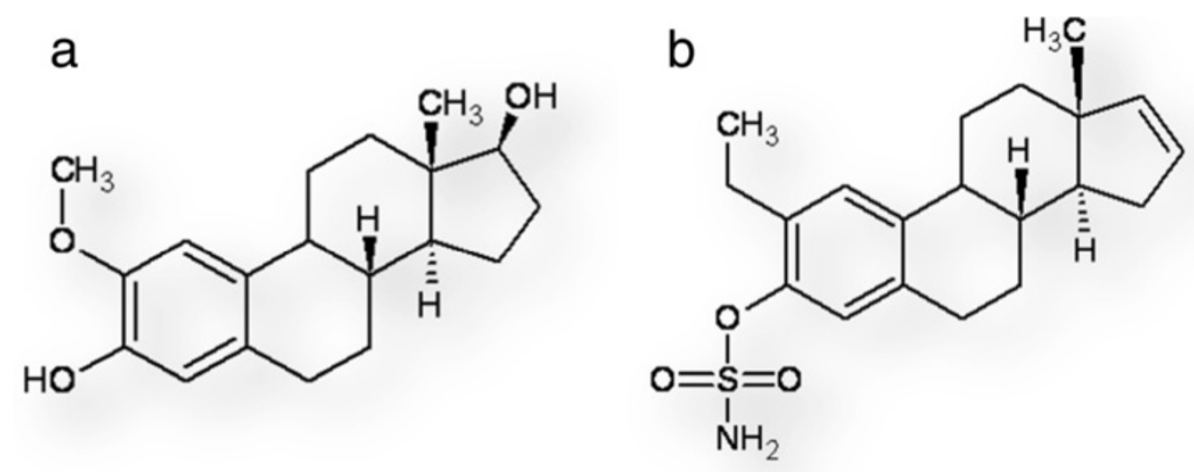

Figure 1 Structure of 2-ME and ESE-16. (a) shows the parent compound, (17 beta)-2-methoxyestra-1,3,5(10)-triene-3,17-diol (2-methoxyestradiol). (b) indicates the substitutions at position 2, 3 and 17 of 2-ethyl-3-O-sulphamoyl-estra-1,3,5(10)16-tetraene (ESE-16), a sulphamoylated 2-ME analogue [33].

Pharmacodynamics of 2-ME appeared to be desirable in the treatment of neoplasms, but the pharmacokinetic picture proved problematic. 2-ME has a short half-life and a poor bioavailability. Being a target for $17 \beta$-hydroxysteroid dehydrogenase-mediated metabolism [10-13], 2-ME is metabolized with conjunction at the 3 and 17 positions, together with oxidation at the 17 position [10]. Strategies have been considered to overcome this rapid biodegradation and to improve its bioavailability. These strategies include the design of nanocrystal dispersion techniques (such as Panzem $\mathrm{NCD}^{\mathrm{TM}}$ ) [3], finding new methods of delivery such as encapsulation [14] and the design of 2-ME analogues [15-20].

The design of 2-ME analogues aimed to enhance the already present anti-mitotic and anti-angiogenic properties of 2-ME itself $[20,21]$. Dehydration at the metabolically active 17 position allowed retention of cytotoxic and anti-tubulin characteristics together with a decreased metabolic breakdown [22,23]. When combined with a substitution at position 3 to increase potency, 3-carboxyamide-2-methoxyestra-1,3,5 (10)16tetraene demonstrated suitable anti-mitotic and antimicrotubule properties with an improved pharmacokinetic profile in vitro and in vivo [22].

Sulphamate substitutions on estrogen molecule analogues increase the estrogenic bioavailability due to avoidance of the first hepatic bypass metabolism [24]. This is attributed to the sulpha moieties' ability to reversibly bind to carbonic anhydrase II (CAII) in erythrocytes, followed by a slow release into the plasma $[24,25]$. CAIX is overexpressed in the immediate tumor environment giving neoplastic cells a growth advantage in their acidic and hypoxic extracellular milieu [26,27]. CAs also promote extracellular acidic activation of the metalloproteinases thereby enhancing the neoplastic cell invasiveness [28]. Therefore selective inhibition of CAIX provides a promising mechanism to manipulate the extracellular tumor milieu and to curtail metastatic tendencies [27].
2-Methoxyestradiol-3,17-O,O-bis-sulfamate (2-MEbis MATE) is a 2-ME analogue, which, by adding a sulpha moiety at position 3 , fulfills two objectives: increasing the anti-mitotic and spindle disruption capacities (position 3 modification) and increasing the bioavailability with the sulpha group [11,29-32]. Literature reported a more potent anti-mitotic (10-fold), anti-spindle and anti-angiogenic (60-fold) effect of 2-MEbisMATE when compared to 2-ME in vitro and in vivo $[11,29,32]$.

Although 2-MEbisMATE has a positive profile of anticancer and anti-angiogenic activities, potency and specificity in CAIX binding needed to be improved. Stander et al. designed a range of 3 sulphamoylated 2-ME analogues in silico by modifying the 2- and 17 positions with moieties known to improve the anti-mitotic activity and to increase the compounds' half-life [33]. The designed compounds were analyzed using a molecular modeling simulation and docking software, namely AutoDockTools4, to determine the best binders to the tubulin colchicine binding site and to CAIX [33].

2-Ethyl-3-O-sulphamoyl-estra-1,3,5(10)16-tetraene (ESE16) (Figure 1b) is one of the novel in silico-designed sulphamoylated 2-ME analogues that needs still to be fully investigated for its potential anti-proliferative characteristics. ESE-16 is not currently commercially available. In silico modeling analysis indicated a significant preference of CAIX over CAII binding, presenting a method to deliver the drug more specifically to acidic tumor environments. Our laboratory has established the anti-proliferative action of ESE-16 at nanomolar concentrations in cell lines including MCF-7 breast cancer cells (estrogen-receptor positive), metastatic MDA-MB-231 breast cancer cells, non-tumorigenic MCF-12A breast cells and SNO nonkeratinizing squamous epithelium cancer [33].

This study aimed to determine whether the novel in silico-designed 2ME analogue, ESE-16, retained the previously described anti-proliferative properties of the parent compound in vitro. Since the compound 
was designed to bind to the colchicine site of the microtubules, the effect of ESE-16 on the spindle integrity was determined. Effect of this spindle disruption on cell cycle progression and resultant induction of programmed cell death pathways were investigated.

\section{Results}

\section{Cell cycle}

Flow cytometry was used to determine the effect of ESE-16 on the progression of exposed cells through the cell cycle, thus indicating an influence on cell viability. Results were calculated as percentage cells in each stage of the cell cycle. Cell cycle distribution of the cells propagated in growth medium (negative control) revealed an average of $50.82 \pm 2.36 \%$ in the $G_{1}$ phase, $21.41 \pm 1.85 \%$ in the $S$ phase and $21.73 \pm 2.61 \%$ in the $G_{2} / M$ phase (Figure 2ia). Only $0.55 \pm 0.19 \%$ of the cells were present in sub- $G_{1}$ population. There was no statistically significant difference between cells propagated in growth medium (negative control) and the DMSO vehicle control sample, both representing a cell population in logarithmic growth (Figure 2ib). Cell cycle distribution changed significantly with actinomycin D- and ESE-16 exposure. A statistically significant increase of cells in sub- $\mathrm{G}_{1}$ was demonstrated in the actinomycin D sample $(4.93 \pm 2.7 \%, P=0.04)$ (Figure 2ic) and the ESE-16-treated cells $(27.93 \pm 3.86 \%$,
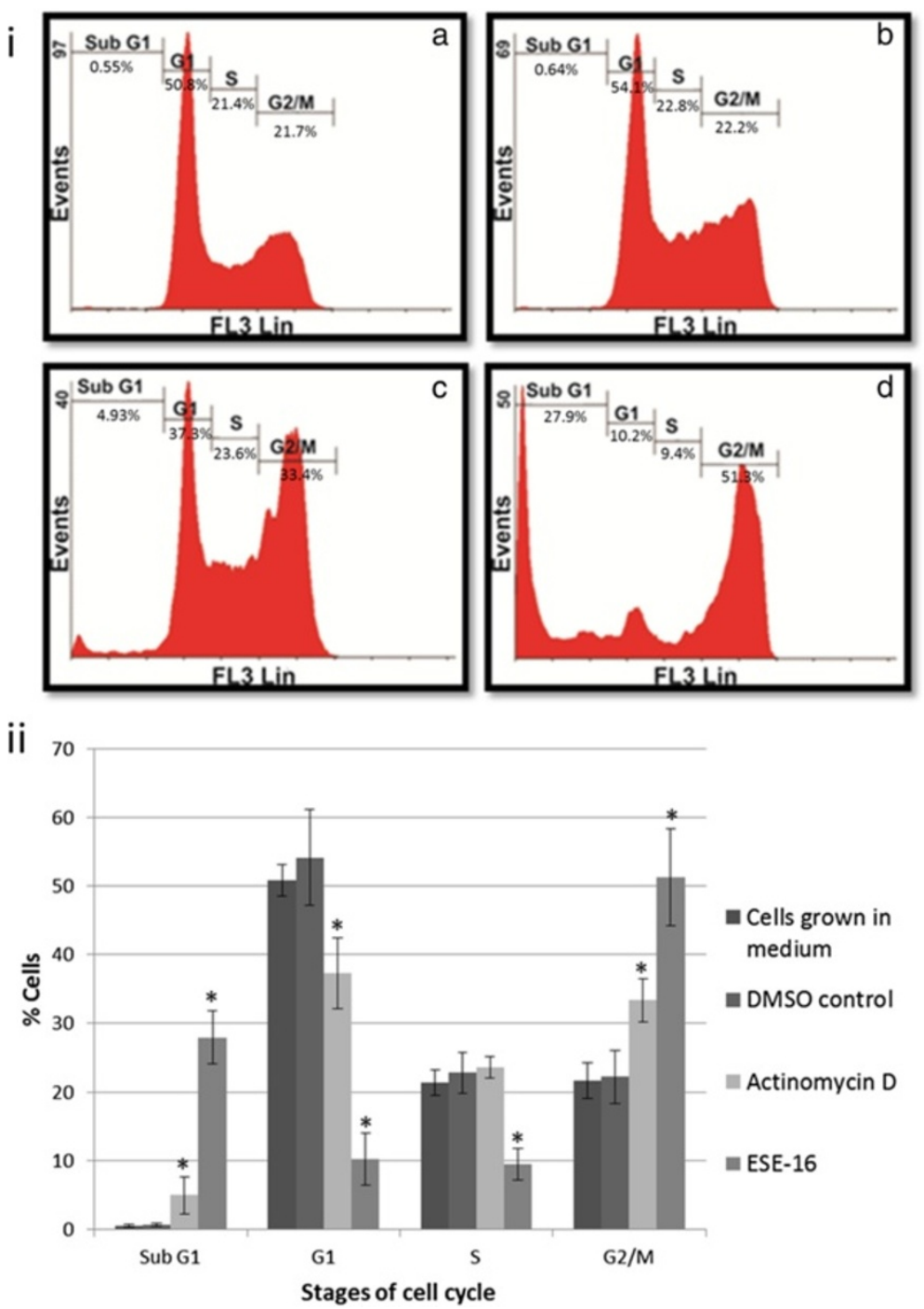

Figure 2 Cell cycle analysis after 24 hour exposure to ESE-16. (2i) Histograms derived from flow cytometry comparing cell distribution within the cell cycle between control samples and ESE-16 treated cells. (2ia) Cell cycle distribution of cells grown in medium only. (2ib) Cells exposed to DMSO as a vehicle control. (2ic) Cells exposed to actinomycin D as a positive apoptosis control. (2id) Cells exposed to ESE-16 demonstrating an increase in $G_{2} / M$ and sub- $G_{1}$ populations with a concurrent decrease in $G_{1}$ - and $S$ phase. (2ii) Graphical representation of the histogram results. (* indicates a statistically significant difference when compared to DMSO vehicle control samples with a $P$ value of $<0.05$ ). Standard deviation is indicated by T-bars. 
$P=0.0002$ ) (Figure $2 \mathrm{id}$ ). $\mathrm{G}_{1}$ populations were significantly decreased, to $37.29 \pm 5.08 \%(P=0.028)$ and $10.16 \pm 3.79 \%$ $(P=0.0007)$ of the cell population in actinomycin $\mathrm{D}$ - and ESE-16-treated cells respectively. ESE-16 showed a decrease in viable cells $\left(G_{1}\right.$ - and $S$ phases) and a distinct increase of cells in $\mathrm{G}_{2} / \mathrm{M}$ phase $(51.28 \pm 7.09 \%, P=0.0034)$. Figure $2 \mathrm{ii}$ summarizes the flow cytometric data of the cell cycle comparing the distribution of cells within the cell cycle in the various samples.

\section{Apoptosis studies}

In order to detect and to discriminate between the induction of apoptosis, necrosis and viable cells, flow cytometric analysis using labeled annexin antibodies for the detection of phosphatidylserine flip in ESE-16-exposed cell membranes was done. Analysis of the data generated from dot plots (Figure 3i) via Cyflogic version 1.2.1 software revealed that in a healthy cell population (DMSO as a vehicle control), $92.8 \pm 1.84 \%$ of the cells were viable, with $7.02 \pm 1.83 \%$ undergoing apoptosis and an insignificant $0.16 \pm 0.02 \%$ in necrosis. There were satistically insignificant differences between cells propagated in growth medium and DSMO vehicle controls. Actinomycin D induced apoptosis $(21.28 \pm 1.76 \%, P=0.0006)$, with a significant decrease of viable cells $(77.68 \pm 1.89 \%, P=0.0005)$. A decrease in cell viability was demonstrated in the ESE-16-exposed cells $(64.22 \pm 4.67 \%, P=0.0006)$, with a corresponding rise in apoptotic cell numbers $(27.32 \pm 2.67 \%, P=0.0004)$. There was no significant difference in the proportion of necrotic cells between the samples $(P=0.08)$. Results are summarized graphically in Figure 3ii.

\section{Cyclin B1 detection}

A cyclin B1-phycoerythrin conjugated antibody (MilliMark $^{\text {Tix }}$ Anti-Cyclin B1-PE, clone GNS3 (8A5D12)) was used to quantify cyclin B1 protein up-regulation in ESE-16-treated HeLa cells by employing flow cytometric analyses. This was conducted to determine the compound's ability to induce a metaphase block. Figure 4i displays representative scatter plots, with the fluorescent intensity of the PE-conjugated cyclin B1 antibody plotted against forward scatter as a determinant of cells size (Figure 4ia and ib) and side scatter indicative of cell complexity (Figure 4ic and id). Scatter plots displayed a higher fluorescent signal in more complex and smaller sized cells which are representative of cells in metaphase [34,35]. Figure 4ii shows the intensity histogram, demonstrating an increased intensity and a right shift of the ESE-16-exposed cells. A $2.47 \pm 0.49$-fold increase of cyclin B1 expression $(P<0.05)$ in the ESE-16-exposed cells was revealed when compared to the DMSO vehicle control.

\section{Aggresome detection: Autophagy}

In order to evaluate the induction of autophagy in ESE16-treated cells, flow cytometric quantification of aggresome formation was conducted. Using the formula provide in the manufacturer's protocol, the aggresome activity factor (AAF) was calculated. According to the manafacture's protocol, an AAF of more than 25 is regarded as a statistically significant increase in aggresome formation. There was no statistically significant difference between cells propagated in growth medium and DMSO vehicle control samples. Figure 5 is a graphic representation of the AAF of tamoxifen- and ESE-16-treated cells, calculated at $44.3 \pm 6.36$ and $40.7 \pm 0.53$ repectively. Data indicate that ESE-16 induces aggressome formation, indicative of autophagy.

\section{Autophagy-related protein LC3 B determination}

Flow cytometric analysis of autophagy-related protein LC3 B expression was done to quantify the formation of autosomal vacuoles in ESE-16-eposed HeLa cells. The MAP1LC3 B rabbit antibody (Biosensis, Thebarton, Australia) was utilized and the FL1 fluorescence of at least 10000 cells were analyzed per repeat. There was a statistically significant increase of LC3 B within the tamoxifen (x mean FL1 $=106.5 \pm 11.6 ; P=0.041$ ) and ESE-16-exposed cells ( $\mathrm{x}$ mean FL1 $=81.2 \pm 4.08$; $P=0.040)$ when compared to the DMSO vehicle control $(\mathrm{x}$ mean FL1 $=66.6 \pm 0.82)$ (Figure 6).

\section{Signal transduction: quantification of caspases $\mathbf{8}$ and $\mathbf{3}$}

The FLICE/Caspase 8 colorimetric kit was used to determine caspase 8 activation in cell lysates of the ESE-16 exposed HeLa cells and of the relevant controls. There was no statistically significant difference noted between readings of cells propagated in growth medium only, DMSO vehicle and actinomycin D controls. A $1.9 \pm 0.4$-fold increase in caspase 8 induction in the ESE-16-exposed HeLa cells was observed when compared to the baseline ( $P$-value 0.04 ) (Figure 7). Caspase 3 activity in cell lysates was measured using the BioVision Caspase-3/CPP32 Colorimetric Assay Kit. Cells propagated in growth medium and DMSO vehicle controls showed no statistical difference between these results. A statistically significant up-regulation of caspase 3 activity in the actinomycin $D$ positive control $(3.75 \pm 0.21$-fold increase, $P=0.011)$ was noted and a pronounced increase in the ESE-16-treated cells (8.03 \pm 0.21 -fold increase, $P=0.008)$ (Figure 7).

\section{Polarization-optical transmitted light differential interference contrast microscopy (PlasDIC)}

To substantiate flow cytometric data and to evaluate ESE-16's anti-proliferative effects, PlasDIC microscopy was used. Cells exposed to DMSO as a vehicle control (v/v\%) (Figure 8a) continued to grow in a logarithmic 

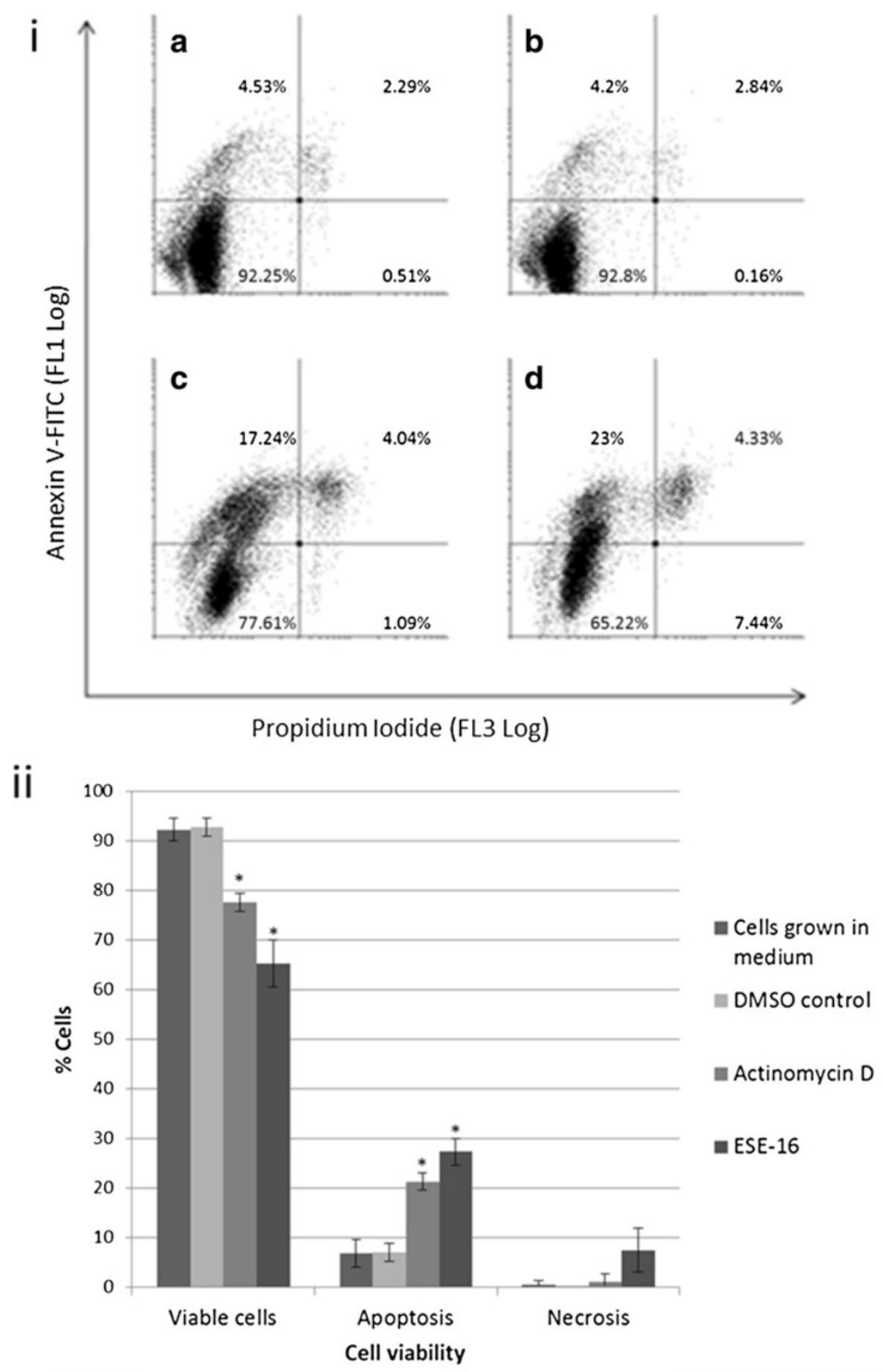

Figure 3 Analysis of HeLa cell viability after 24 hour ESE-16 exposure. Apoptosis was determined by flow cytometric quantification of phosphatidylserine-flip. (3i) Dots plots of HeLa cells after 24 hour exposure to growth medium (3ia), DMSO vehicle control (3ib), actinomycin D positive apoptosis control (3ic) and ESE-15 (3id). A statistically significant decrease of viable cells was seen in actinomycin D- and ESE-16-exposed cells with a concurrent increase of apoptotic cells. There were no statistically significant differences observed between cells propagated in growth medium only and DMSO vehicle controls in any of the cell cycle categories. No significant difference was calculated in the amount of necrotic cells in all samples. (3ii) Graphical representation of the dot plot data (* $P<0.05$, standard deviation represented by T-bars).

manner resulting in confluent cells in various stages of mitosis (mostly interphase). Cells treated with tamoxifen revealed increased presence of vacuolar structures (most likely to be autophagosomes) and cells in distress (cell protrusions) (Figure $8 \mathrm{~b}$ ). Cells exposed to actinomycin D revealed apoptotic bodies, multiple shrunken cells, ghost 

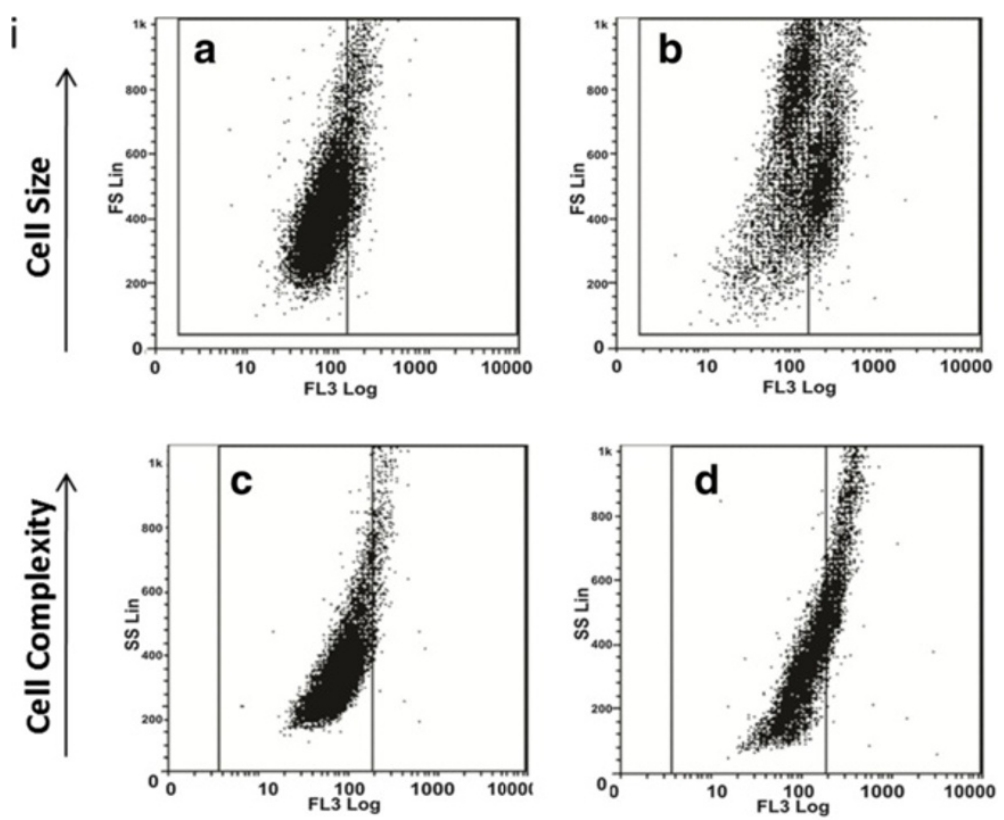

ii

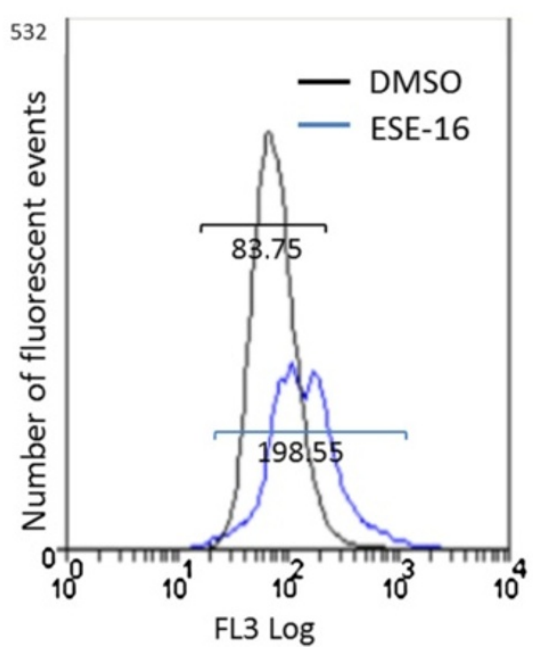

Figure 4 Flow cytometric evaluation of cyclin B1 up-regulation in HeLa cells. (4i) Dot plots of ESE-16 exposed cells (b and d) were compared to the DMSO vehicle control (a and $\mathbf{c}$ ). FL3 log fluoresce intensity was plotted against cell size determined by forward scatter (a and b) and cell complexity as established with side scatter (c and $\mathbf{d}$ ). An increase in expression of cyclin B1 in the ESE-16-treated cells was observed in the smaller (b) and more complex (d) cells. (4ii) Intensity histogram of cyclin B1 expression within the DMSO vehicle control (black) and ESE-16-exposed cells (blue) demonstrating an increase in intensity and a right shift in the drug-exposed cells.

cells and scattered cell debris (Figure 8c). Shrunken and round cells in metaphase block, the formation of apoptotic bodies, as well as evidence of cell debris were visible in the ESE-16-treated HeLa cells (Figure 8d). All treated samples displayed a decrease in cell density.

\section{Fluorescent microscopy}

In order to substantiate autophagy induction, a fluorescent microscopic technique using monodansylcadaverine (MDC) was employed as described by Laane et al. [36]. Figure 9a is a representative image of HeLa cells exposed to DMSO as a vehicle control which displayed confluent growth and non-specific MDC staining. Cells exposed to tamoxifen as the positive autophagy control demonstrated the formation of MDC-positive vacuoles (Figure 9b), as did the ESE-16-exposed cells (Figure 9c). A UV filter with excitation $380 \mathrm{~nm}$ and emission $420 \mathrm{~nm}$ was used for MDC staining detection.

\section{Transmission electron microscopy}

TEM was used to analyze detailed intracellular and membrane properties of HeLa cells exposed to ESE-16 in order to demonstrate morphological evidence of autophagic and apoptotic cell death, both of which were 


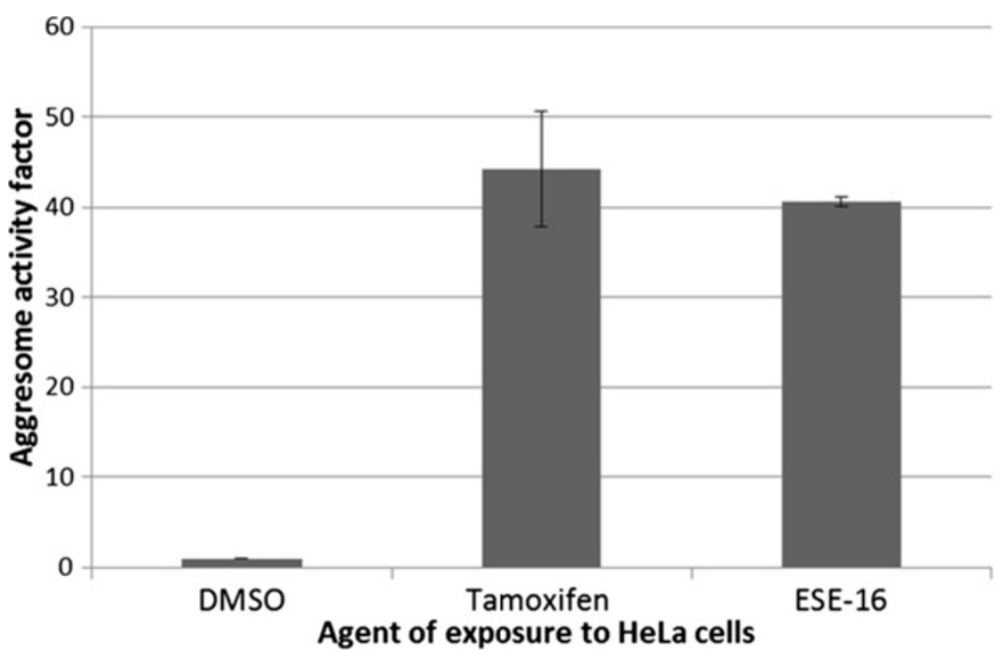

Figure 5 Aggresome activity factor in ESE-16-exposed HeLa cells. Cells treated with tamoxifen and ESE-16 was compared to the negative DMSO vehicle control. Standard deviations are annotated with T-bars. An AAF > 25 represents a significant increase in intracellular aggresome formation, strongly indicative of autophagy (standard deviation represented by T-bars).

hypothesized to be caused by ESE-16. Figure 10ai demonstrates the smooth cell membrane with normal cell protrusions (Figure 10aii) of cells exposed to the DMSO vehicle control. Comparative cellular morphology to cells propagated in growth medium was observed (not shown). Intracellular organelles including mitochondria, nucleoli and nuclear membranes are clearly identifiable, with no vacuolar formation. In contrast, cells exposed to the positive control agents, tamoxifen and actinomycin D, displayed characteristics of cellular distress and processes of autophagy and apoptosis respectively. Figure 10bi shows the marked increase of vacuolar structures in response to tamoxifen exposure. These vacuolar structures were most likely autophagosomes in the light of increased LC3 B expression observed as determined by flow cytometry. The latter observation was further supported by an increase in aggresomes demonstrated via a significant AAF value. Cells are smaller in size, and the nuclear membrane, nucleolus and cell membrane are still intact. Figure 10bii shows one of the vacuolar structures (most likely an autophagosome), demonstrating the engulfed cellular contents and organelles within a membrane. Actinomycin D treatment had a pronounced effect on cell membrane structure, with an increase of membrane protrusions (Figure 10ci and cii). Additionally, signs of apoptosis are evident and include pyknosis, karyorhexis and the presence of apoptotic bodies. Figure 10d demonstrates the effect that ESE16 exposure has on HeLa cells. A significantly distressed cell (representative image of cells treated with ESE-16) in the process of undergoing both apoptosis and autophagy is depicted (Figure 10di). Combination of cell death types I and II are represented by the characteristic apoptotic body formation, chromatin hypercondensation and an increased number of cell membrane protrusions of the former and the presence of numerous vacuolar structures (most likely autophagosomes) as part of the latter. The nuclear membrane is absent. Vacuolar structures and organelles such as Golgi bodies were identified (Figure 10dii).

\section{Confocal microscopy}

In order to observe the effects of ESE-16 on HeLa cell cytoskeletal microtubule architecture, confocal microscopy was used to visualize $\alpha$-tubulin. Figure 11a is a representative image of HeLa cells exposed to the DMSO vehicle control. Confluency of cell growth in various stages of mitosis (mostly interphase) was demonstrated with organized spindle formation visible within these cells. A cell undergoing telophase is shown in Figure 11aii with the chromatids being separated by an organised and functional spindle formation. Cells were exposed to 2-ME as a positive control for spindle depolymerization. Figure 11bi and Figure 5bii demonstrate cells in metaphase block and disorganized tubulin structure after 2-ME exposure with a decrease in cell density. Figure 11c depicts the effect that ESE-16 exposure has on the HeLa cell microskeleton. Total disintegration of the tubulin network is visible in Figure 11ci and cii. Additional evidence of apoptosis was identified in these cells and included margination of DNA, a decrease in cell density and apoptotic body formation.

\section{Discussion}

In order to combine and enhance the anti-cancer characteristics of 2-ME with the advantages gained by strategic modification previously mentioned, ESE-16 was in silico-designed. Dose-dependent studies over a 24-hour period were conducted in our laboratory and 


\section{a}

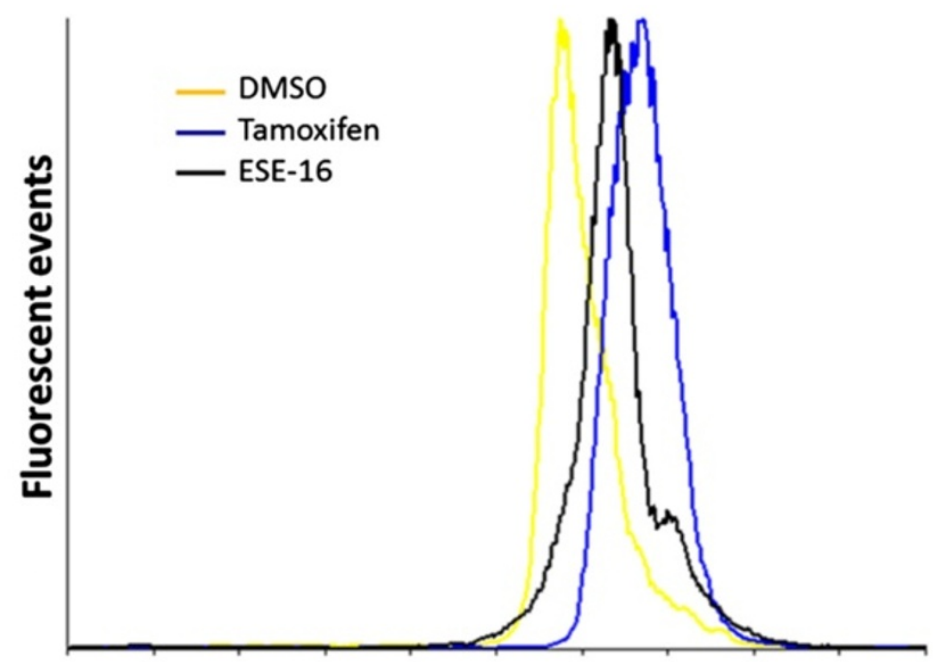

FL1 Log

\section{b}

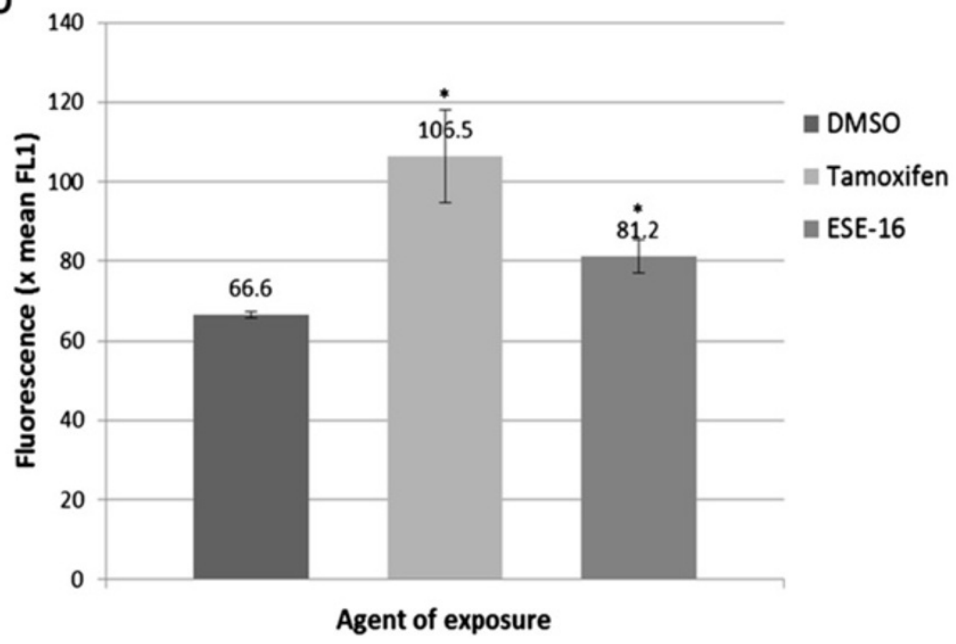

Figure 6 Autophagy-related protein LC3 B determination in ESE-16-exposed HeLa cells. (a) Overlay histogram of LC3 B expression in HeLa cells exposed to the DMSO vehicle control (yellow), tamoxifen (blue) and ESE-16 (black), demonstrating a right shift in the treated samples. (b) Graphic representation of the increase in LC3 B fluorescence between the DMSO vehicle control and ESE-16-exposed HeLa cells $\left({ }^{*} P<0.05\right.$, standard deviation represented by T-bars).

an $\mathrm{IC}_{50}$ of $0.5 \mu \mathrm{M}$ on HeLa cervical adenocarcinoma cells using the crystal violet staining method was established (data not shown). This showed an increased potency when compared to 2-ME, which decreased HeLa cell numbers to $60 \%$ after exposure to $1 \mu \mathrm{M} 2$-ME for 72 hours $[37,38]$. The mechanisms of cell death induced by ESE-16 were further investigated in this study.

Confocal images obtained where HeLa cells were exposed to $0.5 \mu \mathrm{M}$ ESE- 16 for 24 hours and stained with anti-tubulin $\alpha$ antibodies revealed disintegration of tubulin structure, supporting the previous report of microtubule abrogation in MDA-MB-231 cells [33]. These results confirmed ESE-16 as a spindle poison, resulting in the $G_{2} / M$ block. Light microscopic morphological changes also revealed a marked decrease in cell density, with the remaining cells being mostly shrunken and rounded. Cellular debris was evident, as well as the presence of apoptotic bodies. Fluorescent- and transmission electron microscopy corroborated characteristics of both apoptosis and autophagy.

Cell cycle progression analysis by flow cytometry of ESE-16-exposed HeLa cells demonstrated a metaphase block. Loss of cell membrane asymmetry occurring with the translocation of phosphatidylserine to the outside of the cell during apoptosis induction (PS-flip) was also quantified with flow cytometry. ESE-16-exposed HeLa cells demonstrated a decrease in cell viability to $64.22 \%$, with a concomitant increase in the number of cells in 


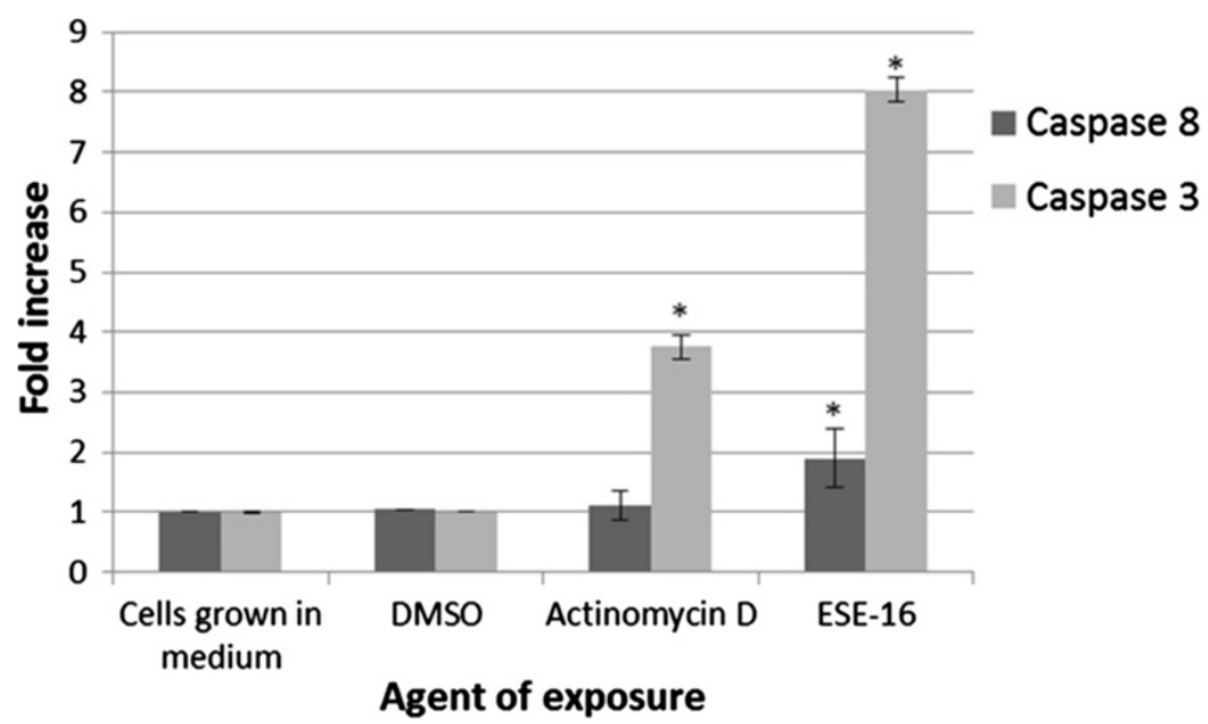

Figure 7 Fold increase in caspase 8 and 3 activity in ESE-16-treated cells. Compound treated cells were compared to cells propagated in growth medium $(\mathrm{MO})$, the DMSO vehicle and actinomycin $\mathrm{D}$ controls ( $P<0.05$, standard deviation represented by T-bars).

apoptosis (27.32\%). Results confirmed prior data from our laboratory that (200 nM) ESE-16-exposed MDA-MB-231 cells showed a $\mathrm{G}_{2} / \mathrm{M}$ block after 24 hours, as well as an increase in the sub- $G_{1}$ fraction, whereas after 48 hours nearly all the cells were present be in the sub- $G_{1}$ fraction [33].

The induction of mitotic block followed by apoptosis (and autophagy) in MCF-7 cells exposed to $1 \mu \mathrm{M} 2-\mathrm{ME}$ for 24 hours has previously been published by our laboratory [6]. Gene expression microarrays showed differential expression of genes mapped to a variety of processes involved in managing the cell in metaphase block and subsequent programmed death induction (including genes involved in microtubule dynamics, cell cycle checkpoints, cyclin B1 degradation, autophagy and apoptotic regulation) [6].

In the light of the mitotic block demonstrated in HeLa cells exposed to $0.5 \mu \mathrm{M}$ ESE-16 for 24 hours by morphological studies and flow cytometric analysis, levels of cyclin B1 were determined using flow cytometry. An overall 2.47fold increase of cyclin B1 was determined when compared to the vehicle control. A higher fluorescent signal was emitted from the smaller more complex cells (representing cells in metaphase block) when fluorescence against sideand forward scatter was plotted. Up-regulation of cyclin B1 expression corroborated the finding of the cell cycle analysis, in which there was a significant increase in cells in metaphase after ESE-16 exposure. Formation of tetrapoidic cells after mitotic spindle inhibition may have caused forced overexpression of cyclin B1, as well as showing a role of this molecule in cell size determination [34,39].

The fate of a cell in unmitigated mitotic arrest seems to depend on the interplay between cyclin B and MCL1 levels [40]. Both MCL1 and cyclin B are at peak concentrations just after spindle poisons have induced the mitotic block: the former to apprehend the onset of apoptosis while cellular restoration is being attempted, and the latter due to the SAC-induced arrest of cell cycle progression due to unattached kinetochores [41]. A rapid upregulation of cyclin $\mathrm{B} 1$ was demonstrated by Newman et al. in MCF-7 cells on exposure to $500 \mathrm{nM}$ taxol, 2-ME and 2MEbisMATE after 24 hours [42]. The increase in cyclin B blocks the progression of the cell cycle and apoptosis until it is degraded, at which point the cell is able to resume its cycle or undergo apoptosis. After 48 hours, the levels of cyclin B deteriorated in the exposed MCF-7 cells, allowing the cells to undergo apoptosis via p53 induction (2-ME did not induce p53 at that concentration) [42]. Additionally, the anti-apoptotic BCL2 protein had been deactivated by phosphorylation in the 2-MEbisMATE and taxol-treated MCF-7 cells after 24 hours of exposure [42].

ESE-16 causes a disrupted spindle assembly and may activate the spindle assembly checkpoint (SAC) resulting in mitotic block and inducing apoptosis [43]. Increased cyclin B1 levels may also be due to ESE-16 blocking the mitotic escape routes downstream of the checkpoint which prevents the premature exit of cells from the induced apoptosis pathways, thereby preventing resistance to the compound's effects and increasing its anti-tumorigenic properties. The latter serves to slow down proteolytic breakdown of cyclin B1, allowing an increased opportunity for death initiation [43].

2-ME has been implicated in induction of the extrinsic apoptotic pathway in several cell lines [44]. Both caspase 8 and 3 were up-regulated after a 24 hour exposure of HeLa cells to $0.5 \mu \mathrm{M}$ ESE-16 in this study. Since caspase 3 

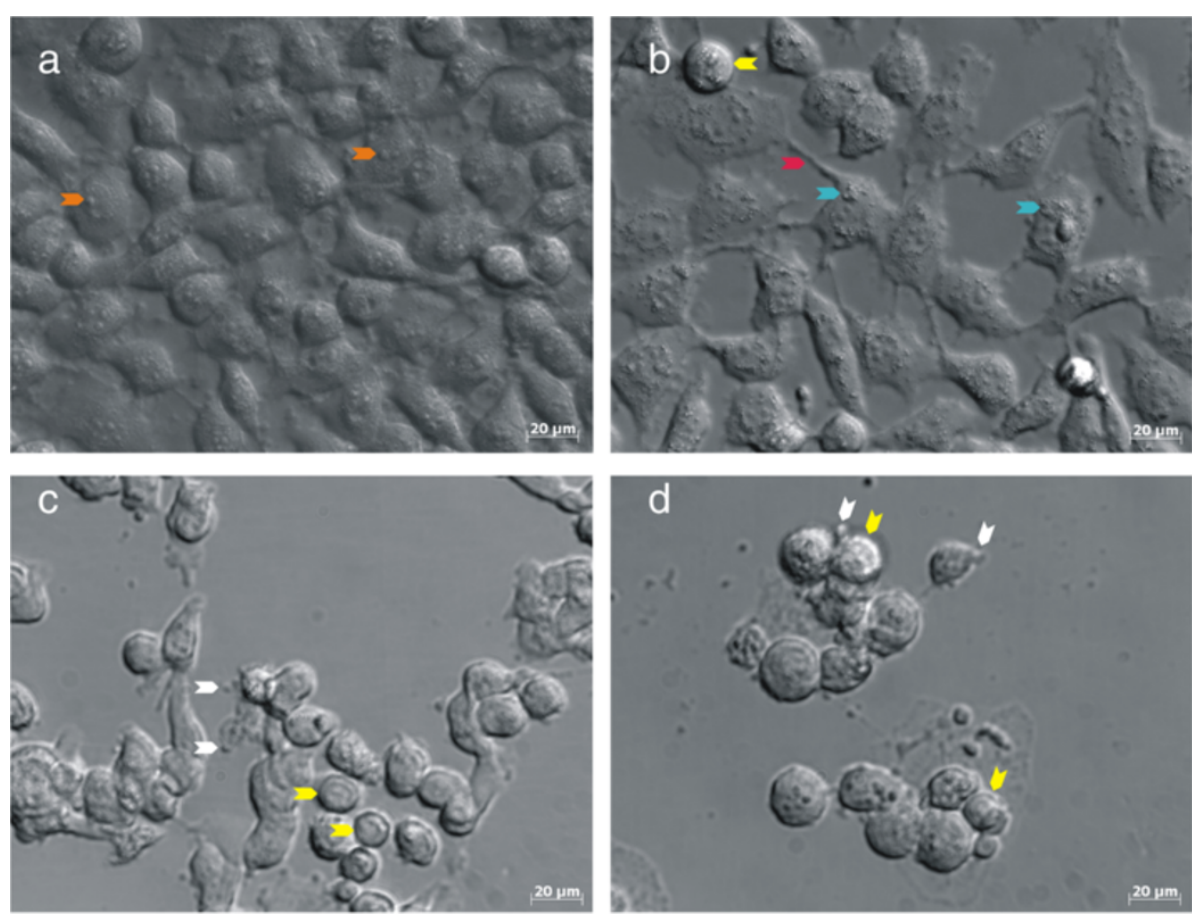

Figure 8 PlasDIC micrographs of HeLa cells after a 24 hour exposure. (a) DMSO (vehicle control) exposure demonstrated confluent growth of HeLa cells. Cells were mostly in interphase. (b) Tamoxifen exposure (positive autophagy control) demonstrated a reduction in cell density and an increase in vacuolar structures and cell protrusions (cell distress). (c) Actinomycin D exposure (positive apoptosis control) resulted in a reduction in cell density, apoptotic bodies, shrunken cells, ghost cells and cellular debris. (d) HeLa cells exposed to $0.5 \mu \mathrm{M}$ ESE-16, demonstrating the hallmarks of metaphase block and apoptosis. (Arrow colour key: orange = nucleoli; blue = vacuolar structures; yellow = rounded cells in metaphase; red = cell protrusion; white = apoptotic bodies).

is an executioner caspase common to both intrinsic and extrinsic pathways, the deduction that ESE-16 induces a caspase-dependent mode of cell death can be made.

Induction of the intrinsic apoptotic pathway with the release of cytochrome $c$ causes the formation of the active apoptosome, resulting in the activation of caspase 9, which in turn cleaves the downstream executioner caspases 3, 6 and /or 7 [45]. Mitochondrial membrane potential is affected in ESE-16-exposed HeLa cells indicates involvement of the intrinsic apoptotic pathway. The latter was substantiated by the demonstration of caspase 6 activity [18]. The increase in caspase 8 activity in this study indicates the possibility of an extrinsic pathway concomitantly with the intrinsic pathway.

Evidence of autophagy occurring simultaneously to apoptosis in HeLa cells exposed to 0.5 $\mu \mathrm{M}$ ESE-16 was indicated via MDC fluorescent microscopy and TEM analysis. In order to support these findings, the AAF was calculated in a flow cytometric assay based on the principle that misfolded proteins are relegated to aggresomes which

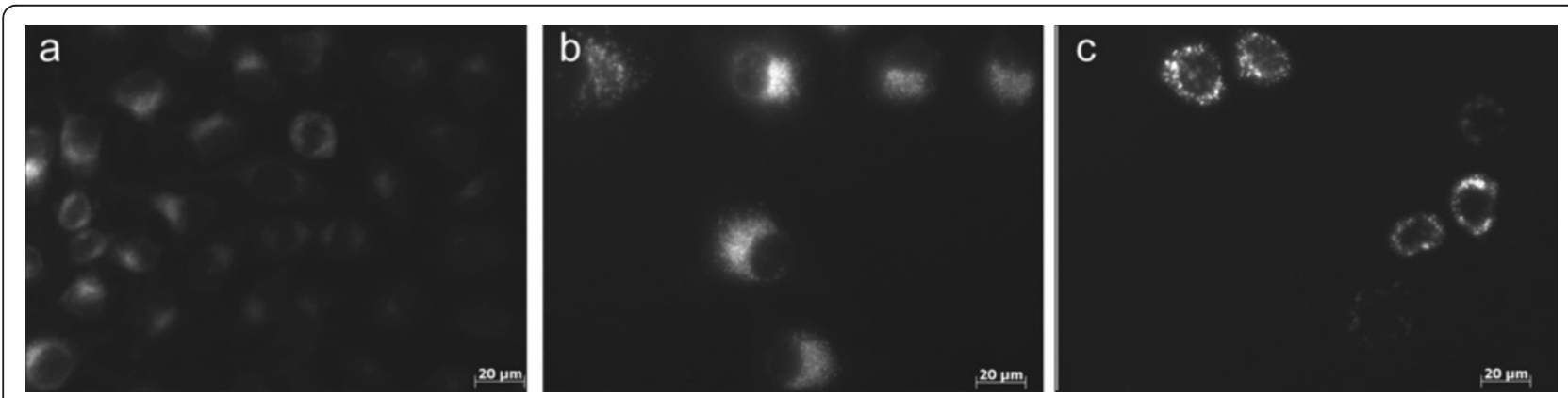

Figure 9 MDC fluorescence microscopy of ESE-16-exposed HeLa cells. (a) DMSO (vehicle control) demonstrated dividing cells with satisfactory confluency and non-specific MDC staining. (b) Tamoxifen-exposed cells demonstrating MDC-stained vacuoles. (c) ESE-16-exposed cells demonstrated a compromised cell density and the formation of MDC-stained vacuoles. 

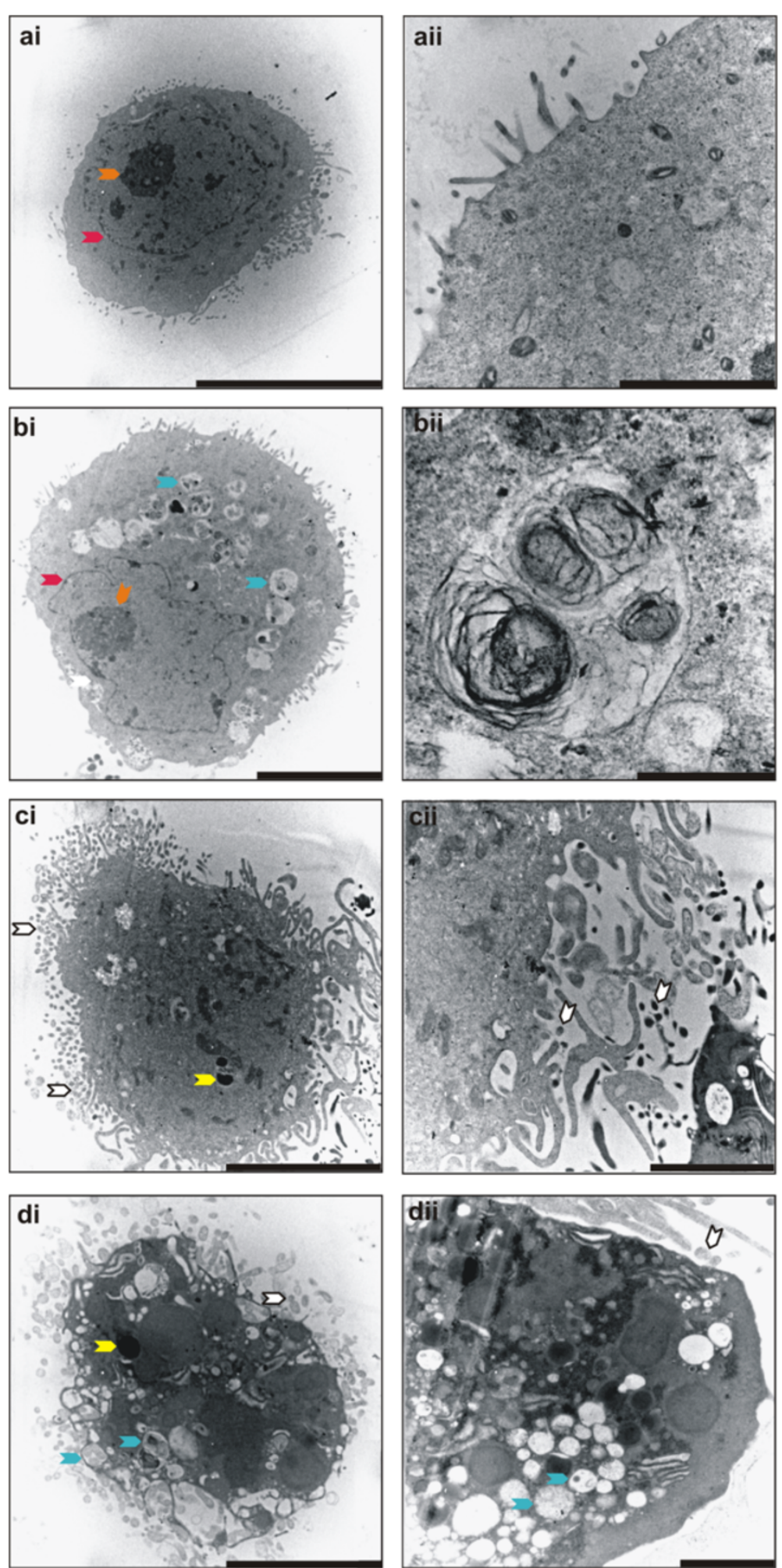

Figure 10 (See legend on next page.) 
(See figure on previous page.)

Figure 10 Transmission electron microscopy of exposed HeLa cells. (ai) HeLa cell exposed to the DMSO vehicle control which demonstrated a smooth well-defined cell membrane with normal cell protrusions, as well as an intact nuclear membrane. Organelles such as mitochondria are identifiable (scale bar: $10 \mu \mathrm{m}$ ). (aii) Representative image of the cell membrane showing normal cellular protrusions (scale bar: $2 \mu \mathrm{m})$. (bi) HeLa cell after exposure to tamoxifen (positive autophagy control). Cells displayed vacuolar structures, although the cell membrane, nucleolus and nuclear membrane remained intact. (bii) Representative image of a vacuolar structure (scale bars represent $5 \mu \mathrm{m}$ in (bi) and $0.5 \mu \mathrm{m}$ in (bii)). Figure (ci) and (cii) are representative images of actinomycin D-exposed cells showing apoptotic bodies, pyknosis and an increase in the number of cellular membrane protrusions. The nuclear membrane is absent (scale bars: $5 \mu \mathrm{m}$ in (ci) and $2 \mu \mathrm{m}$ in (cii)). Images (di) and (dii) of ESE-16-treated cells showed the presence of vacuolar structures (similar to the tamoxifen control), apoptotic bodies, nuclear condensation, increased membrane protrusions and absence of the nuclear membrane demonstrating a cell in distress (scale bars: $5 \mu \mathrm{m}$ (di) and $2 \mu \mathrm{m}$ (dii) respectively). (Arrow colour key: orange $=$ nucleoli; red $=$ nuclear membrane; blue = vacuolar structures; yellow = pyknosis; white = apoptotic bodies).

are cleared by autophagy. Additionally, the quantification of autophagy-related protein LC3 B was done in ESE-16 exposed HeLa cells. LC3 B is required for the formation of autophagosomes [46]. Results demonstrated an increase in the AAF, as well as LC3 B expression in ESE-16-treated cells, thus indicating that autophagy is induced along with apoptosis.

Caspases and Beclin-1 may mediate cross talk between apoptosis and autophagy [47]. When Beclin-1, a B-cell lymphoma 2 (BCL2) homology domain 3 (BH3) family member is bound to BCL2 or BCL-extra long (BCL-XL), its interaction with phosphatidylinositol 3-kinase Catalytic Subunit Type 3 (PI3KC3) along with other proteins which are core to the autophagy-inducing complex, is inhibited, thereby preventing autophagy $[48,49]$. However, Beclin-1 and PI3KC3 are direct substrates of caspases (3, 7 and 8), a process which may be observed during induction of both the intrinsic and extrinsic apoptotic pathway [50]. BCL-2-associated X protein (BAX) over-expression, which induces the intrinsic apoptotic pathway has been shown to cause caspase cleavage of Beclin-1, as does activation of tumor necrosis factor (TNF)-related apoptosisinducing ligand (TRAIL) [51,52]. Once cleaved, the Beclin-1 C-terminal acquires a new apoptotic-promoting function [50]. Autophagy-related protein 4D (Atg4D) cleavage by caspase 3 induces autophagy activity, but has a cytotoxic effect which amplifies apoptosis via the intrinsic mitochondrial pathway [53]. Thus it can be proposed that caspase cleavage of Beclin-1 and Atg4D can prevent protective autophagic induction and the C-fragment of Beclin1 can sensitize cells to pro-apoptotic signals [47]. Crosstalk between autophagy and apoptosis in HeLa cells induced by ESE-16 destruction of microtubule integrity and resultant metaphase block, involves the extrinsic pathway with increased caspase 8 and 3 activity.

\section{Conclusion}

Data from this in vitro study supports the concept that the novel in silico-designed estradiol analogue, ESE-16, may act as a potential anti-cancer drug. ESE-16 induced both autophagy and apoptosis in cervical adenocarcinoma (HeLa) cells in response to a persistent mitotic block caused by microtubule abrogation. An increase in caspases 8 and 3 implicated the extrinsic pathway of induction. The involvement of Beclin-1 as a mediator between autophagy and apoptotis in ESE-16 exposed cells must be established. Future in vivo studies will determine whether this novel anti-neoplastic drug exerts any significant side-effects and whether the in silico-design of our laboratory to increase the compounds' bioavailability was successful.

\section{Materials and methods \\ Reagents}

Dulbecco's Modified Eagle Medium (DMEM) was purchased from Separations (Johannesburg, South Africa). European-grade heat-inactivated fetal calf serum (FCS) and RNase A were obtained from BIOCOM biotech (Pty) Ltd. (Clubview, South Africa). Syringe filters $(0.22 \mu \mathrm{m})$, sterile cell culture flasks and plates were obtained through Sterilab Services (Kempton Park, Johannesburg, South Africa). Penicillin, streptomycin and fungizone were purchased from Highveld Biological (Pty) Ltd. (Sandringham, South Africa), as was the trypsin/versene. Triton X-100, 100\% ethanol, and propidium iodide were purchased from Sigma-Aldrich (St. Louis, Missouri, United States of America (USA). All additional chemicals were of analytical grade and were purchased from Sigma-Aldrich (St Louis, Missouri, USA).

\section{Chemical compound and appropriate controls}

The non-commercially available 2-ethyl-3-O-sulphamoylestra-1,3,5(10)16-tetraene (ESE-16) was synthesized by iThemba (PTY) Ltd. Pharmaceuticals (Modderfontein, Gauteng, South Africa). The $\mathrm{IC}_{50}$ of ESE-16 in HeLa cells was established to be $0.5 \mu \mathrm{M}$ via a crystal violet staining technique in a dose-dependent study (data shown in Additional file 1). As a negative vehicle control, medium of the cell samples were supplemented with an equal concentration of dimethyl sulphoxide (DMSO). The DMSO content of the final dilutions never exceeded $0.1 \%$ (v/v). Positive controls constituted actinomycin $\mathrm{D}$ at a final concentration of $0.1 \mu \mathrm{g} / \mathrm{ml}$ for apoptosis, $20 \mu \mathrm{M}$ tamoxifen for autophagy and $1 \mu \mathrm{M} 2-\mathrm{ME}$ for 

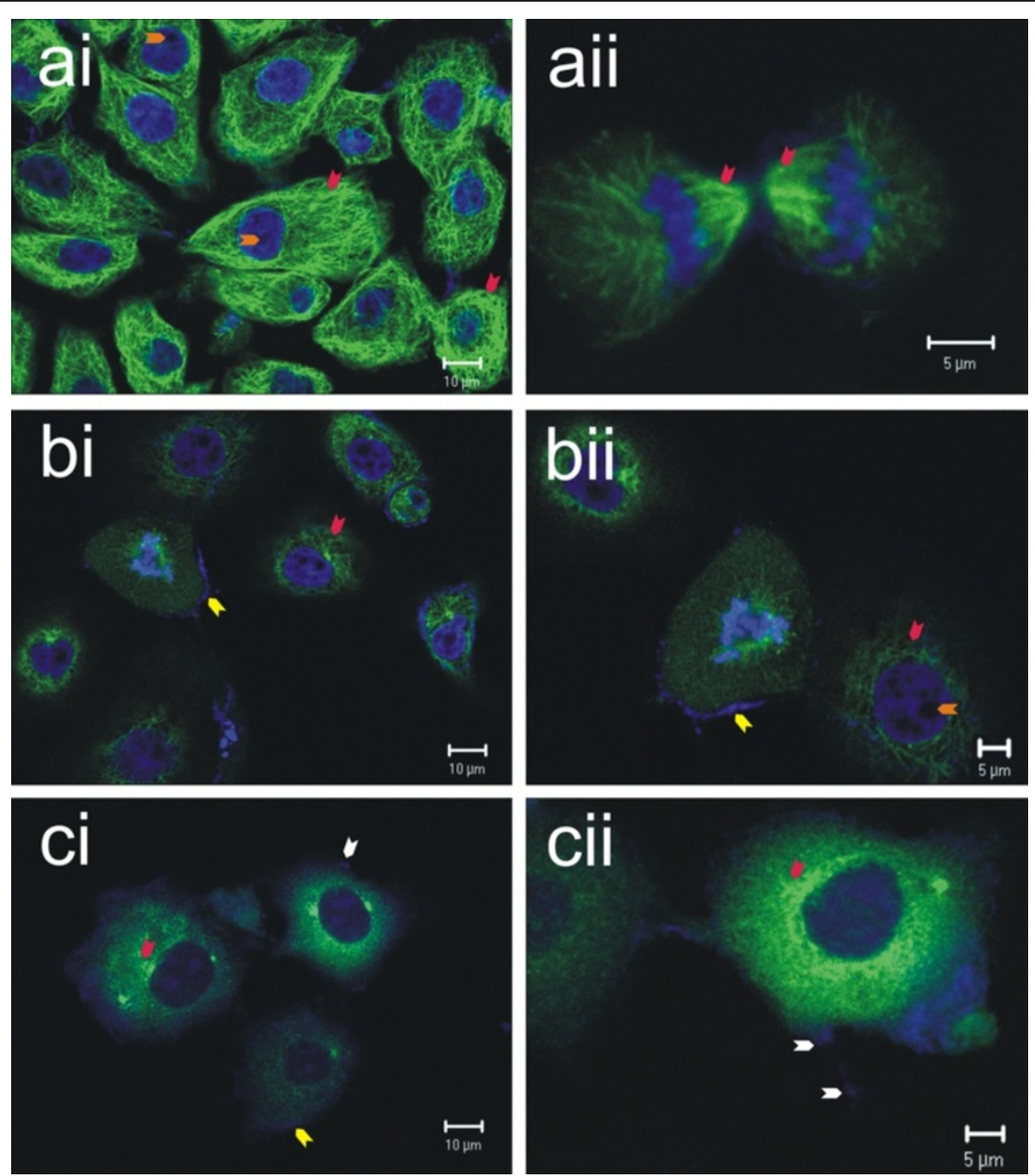

Figure 11 Confocal microscopic immunofluorescent images of the microtubule structure within ESE-16-exposed HeLa cells. Alexa-488 fluorescent labeled tubulin-a antibodies fluoresce green allowing visualization of the tubulin network, while DAPI stained nuclear material blue. (ai) DMSO exposure (vehicle control) demonstrated cell confluency, various stages of cell division and intact organised tubulin networks as seen in medium only exposed cells (not shown). (aii) A cell in telophase, demonstrating intact microskeletal structure. (bi) and (bii) HeLa cells exposed to 2-ME as a positive control for a microtubule depolymerizing agent, demonstrated compromised cell density and cells in metaphase block with disorganised tubulin structures. (ci) and (cii) 24 Hour ESE-16 exposure showed complete tubulin disintegration together with apoptotic body formation, DNA margination and a decrease in cell density. (Arrow colour key: orange = nucleoli; yellow = DNA margination; white = apoptotic bodies; red = microtubules, organized and intact in the DMSO vehicle control, and disintegration in the 2-ME control and ESE-16-treated cells).

microtubule depolymerization (Sigma-Aldrich, St Louis, Missouri, USA).

\section{Cell line and cell culture}

The commercially available tumorigenic human epithelial cervical cell line, namely the HeLa cell line, was acquired from Highveld Biological (Pty) Ltd (Sandringham, Johannesburg, South Africa). HeLa cells were propagated and maintained in $25 \mathrm{~cm}^{2}$ or $75 \mathrm{~cm}^{2}$ tissue culture flasks in a humidified atmosphere at $37^{\circ} \mathrm{C}, 5 \% \mathrm{CO}_{2}$ in a Forma Scientific water-jacketed incubator (Ohio, USA). HeLa cells were cultured in DMEM supplemented with $10 \%$ heat-inactivated FCS $\left(56^{\circ} \mathrm{C}, 30 \mathrm{mi}-\right.$ nutes) for optimal cell growth. $100 \mathrm{U} / \mathrm{ml}$ penicillin G, $100 \mu \mathrm{g} / \mathrm{ml}$ streptomycin and fungizone $(250 \mu \mathrm{g} / \mathrm{L})$ were added to the medium for infection control. Experiments were performed in either six-well plates or $25 \mathrm{~cm}^{2}$ cell culture flasks. For six-well plates, exponentially growing cells were seeded at 350000 cells per well in $3 \mathrm{ml}$ fresh maintenance medium. For $25 \mathrm{~cm}^{2}$ cell culture flasks, exponentially growing HeLa cells were seeded at $1 \times 10^{6}$ cells per flask to a final volume of $5 \mathrm{ml}$ of maintenance medium. After a 24-hour incubation period at $37^{\circ} \mathrm{C}$ to allow for cell adherence, cells were exposed to $0.5 \mu \mathrm{M}$ ESE-16 and 
the relevant controls were included. Cells were incubated for a further 24 hours at $37^{\circ} \mathrm{C}$ as the exposure time-frame.

\section{Cell cycle analysis}

Exposed cells were trypsinized and collected for analysis. Cells were centrifuged at $150 \mathrm{~g}$ and subsequently resuspended in $200 \mu \mathrm{l}$ ice-cold PBS containing $0.1 \%$ FCS. Ice-cold $70 \%$ ethanol was added in a drop-wise manner while vortexing gently. Samples were incubated at $4^{\circ} \mathrm{C}$ for a minimum of 12 hours, after which the cells were pelleted by centrifugation. Cells were resuspended in PBS containing propidium iodide $(40 \mu \mathrm{g} / \mathrm{ml})$, RNase A $(100 \mu \mathrm{g} / \mathrm{ml})$ and Triton X-100 $(0.1 \%)$ and incubated while protected from light at $37^{\circ} \mathrm{C}$ for 40 minutes. Analysis entailed measurement of propidium iodide fluorescence (FL3) on a FC500 system flow cytometer (Beckman Coulter, South Africa (PTY) Ltd.) equipped with an air-cooled argon laser excited at $488 \mathrm{~nm}$. Aneuploid and aggregated cells, as well as cell debris were gated out by visual inspection. Cell cycle distributions from generated histograms were expressed as a percentage of cells in each phase.

\section{Apoptosis studies}

Analysis was performed using the BioVision Annexin V-FITC reagent kit acquired from BioVision Research Products (Mountain view, California, USA. The 1X binding buffer (supplied in the kit) was prepared as directed. According to manufacturer's protocol, 500000 exposed cells from each flask were washed in PBS, centrifuged and resuspended in $1 \mathrm{X}$ binding buffer. Double staining was done by adding $1 \mu \mathrm{l}$ Annexin V-FITC and $1.2 \mu \mathrm{l} 40 \mu \mathrm{g} / \mathrm{ml}$ propidium iodide to the cells, which were incubated for five minutes at room temperature in the dark. Annexin V (FL1) and propidium iodide (FL3) fluorescence were measured in 10000 cells per sample with a FACS FC500 System flow cytometer (Beckman Coulter South Africa (Pty) Ltd.) equipped with an air-cooled argon laser excited at $488 \mathrm{~nm}$. Results were expressed as a percentage of cells in three categories namely; viable cells, apoptotic cells and necrotic cells.

\section{Cyclin B1 detection: metaphase block}

Exposed cells were trypsinized, collected, centrifuged and washed with $1 \mathrm{ml}$ ice-cold PBS. Cells were resuspended in $200 \mu \mathrm{l}$ ice-cold PBS containing 0.1\% FCS. Cells were fixed with $10 \mathrm{ml}$ ice-cold $70 \%$ ethanol and stored at $4^{\circ} \mathrm{C}$ for 24 hours. Cells were centrifuged and washed twice with PBS to remove the ethanol. A working antibody solution (Milli-Mark ${ }^{\mathrm{mm}}$ Anti-Cyclin B1-PE, clone GNS3 (8A5D12), Millipore Corporation, Temecula, California, USA) was prepared by diluting the primary antibody in PBS in a 1:5 ratio. A 1:10 antibody solution to $0.1 \%$
Triton X-100 PBS was added per 1 X $10^{6}$ cell sample. Cells were incubated in the conjugated cyclin B1 antibody solution for 40 minutes at $37^{\circ} \mathrm{C}$. Cells were washed with PBS. All procedures after the incubation with the antibody were conducted in a light protected environment. PE (FL3) fluorescence was measured with a FC500 System flow cytometer (Beckman Coulter South Africa (Pty) Ltd.) equipped with an air-cooled argon laser excited at $488 \mathrm{~nm}$. Aggregated and aneuploid cells were excluded from the analysis. 10000 cells were analyzed per sample. Measurement of PE-conjugated cyclin B1 fluorescence of control and exposed HeLa cells was done using the normalized area of the dot-plot.

\section{Autophagy: aggresome detection}

The Enzo Life Sciences' ProteoStat ${ }^{\circ}$ Aggresome Detection Kit was purchased from Enzo Life Sciences Inc. (New York, USA). The kit provided the ProteoStat ${ }^{\circ}$ Aggresome Detection Reagent and the 10X assay buffer. Subsequent to the 24 hour exposure, cells were harvested via trypsinization and resuspended in $200 \mu \mathrm{l}$ PBS prior to adding $4 \%$ formaldehyde in a drop-wise manner while vortexing the tube. Cells were left at room temperature for 30 minutes. Samples were centrifuged and a PBS washing step followed. While vortexing, permeabilizing solution was added in a drop-wise fashion, after which the sample was incubated for 30 minutes on ice. Cells were collected by centrifugation, after which they were washed in PBS. Cells were resuspended diluted ProteoStat ${ }^{\circ}$ Aggresome detection reagent. Cells were incubated at room temperature for 30 minutes in the dark. Fluorescence within 10000 cells of each sample was analyzed in the FL3 channel of the FACS FC500 System flow cytometer (Beckman Coulter, South Africa (Pty) Ltd.) equipped with an air-cooled argon laser excited at $488 \mathrm{~nm}$. After obtaining the mean fluorescence intensity (MFI) for the samples (cells propagated in medium only as the negative control, ESE-16-treated cells and a positive autophagy control), the aggresome activity factor (AAF), as determined according to the supplier's manual, was calculated as follows:

$$
\mathrm{AAF}=100^{*}\left(\mathrm{MFI}_{\mathrm{Rx}}-\mathrm{MFI}_{\mathrm{CONT}}\right) / \mathrm{MFI}_{\mathrm{Rx}}
$$

where AAF is the aggresome activity factor; $\mathrm{MFI}_{\mathrm{Rx}}$ is the mean fluorescence intensity of the treated sample; and $\mathrm{MFI}_{\mathrm{CONT}}$ is the mean fluorescence intensity of the control sample. An AAF of more than 25 was indicative of a positive result and a significant increase in aggresome formation.

\section{Autophagy-related protein LC3 B determination}

After a 24 hour exposure to ESE-16 and the relevant controls, cells were trypsinized and washed with ice-cold PBS. Cells were fixed with $0.01 \%$ paraformaldehyde/PBS 
for $10 \mathrm{~min}$, then pelleted and resuspended in ice-cold PBS. Cells were permeablized with ice-cold methanol $\left(-20^{\circ} \mathrm{C}\right)$, added in a drop-wise manner. Cells were washed twice with cold PBS. Pelleted cells were resuspended in the primary antibody solution (0.5:1000 MAP1LC3 B rabbit antibody (Biosensis, Thebarton, Australia) to PBS, $1 \%$ BSA) and incubated for 2 hours at $4^{\circ} \mathrm{C}$ protected from light. Cells were washed thrice with washing buffer (PBS, 0.05\% Triton, 1\% BSA). Blue carrier protein (FL1) fluorescence was measured with a FC500 System flow cytometer (Beckman Coulter SA (Pty) Ltd.) equipped with an air-cooled argon laser excited at $488 \mathrm{~nm}$. Data from at least 10000 cells were analyzed. Measurement of Blue Carrier Protein-conjugated MAP1LC3 B antibody fluorescence of control and exposed HeLa cells was done, using the normalized area of the dot-plot. An overlay histogram was constructed from the dot plots using Cyflogic version 1.2.1 software (Pertu Therho, Turko, Finland).

\section{Quantification of caspases 8 and 3}

The FLICE/Caspase 8 colorimetric kit was used to determine caspase 8 activation and the BioVision Caspase-3/CPP32 Colorimetric Assay Kit was used to quantify caspase 3 activity. Both kits were purchased from BioVision Research Products (Mountain View, California, USA). Included were the cell lysis buffer, $2 \mathrm{X}$ reaction buffer, $4 \mathrm{mM}$ IETD- $p$ NA (in the caspase 8 kit), $4 \mathrm{mM}$ DEVD- $p \mathrm{NA}$ (in the caspase $3 \mathrm{kit}$ ), $1 \mathrm{M}$ dithiothreitol (DTT) and the dilution buffer. $1-5 \times 10^{6}$ treated cells were pelleted by centrifugation after trypsinization, and resuspended in ice-cold cell lysis buffer and incubated on ice for 10 minutes. Following centrifugation, the supernatant was transferred to eppendorf tubes and placed on ice. The protein concentration was determined using the Pierce ${ }^{\circ}$ BCA protein assay kit (Thermo Fisher Scientific Inc. Rockford, Illinois, USA) as per manufacturers protocol. Protein $(50 \mu \mathrm{g})$ of each assay was diluted in $50 \mu \mathrm{l}$ cell lysis buffer and placed in a 96-well plate, to which an equal volume of $2 \times$ reaction buffer (containing $10 \mathrm{mM}$ DTT) was added. The reaction was initiated by adding $5 \mu \mathrm{LEVD}-p \mathrm{NA}$ for caspase 3 or IETA- $p$ NA for caspase 8 . Plates were incubated for 120 minutes at $37^{\circ} \mathrm{C}$, protected from light and the absorbance was read at $405 \mathrm{mn}$ on the BioTek Epoch multi-volume spectrophotometer system (BioTek Instruments Inc., Analytical Diagnostic Products, Weltevreden Park, South Africa). Background readings from the buffers were first subtracted from the total readings, after which the fold increase of caspase activity was determined by using the DMSO vehicle control as the baseline reading.

\section{Polarization-optical transmitted light differential interference contrast microscopy}

Viable cells $\left(3.5 \times 10^{5}\right)$ determined by trypan blue exclusion, were seeded in six-well plates and allowed to attach for 24 hours. PlasDIC images were obtained using the Zeiss Axiovert-40 microscope (Göttingen, Germany) and Zeiss Axiovert MRm monochrome camera (Carl Zeiss MicroImaging $\mathrm{GmbH}$, Göttingen, Germany) before and after a 24 hour exposure to vehicle controls, positive controls or ESE-16 respectively.

\section{Fluorescent microscopy}

Fluorescent microscopy using monodansylcadaverine (MDC) was employed to determine the effect that ESE-16 has on acidic vesicular organelle formation [36]. After discarding the growth medium, ESE-16 exposed cells (and relevant controls) were incubated in $0.05 \mathrm{mM} \mathrm{MDC}$ for 10 minutes at $37^{\circ} \mathrm{C}$. Cells were washed four times with PBS. Cells were examined with a Zeiss inverted Axiovert CFL40 microscope and Zeiss Axiovert MR monochrome camera (Carl Zeiss (Pty) Ltd., Johannesburg, South Africa). A UV filter with excitation $380 \mathrm{~nm}$ and emission $420 \mathrm{~nm}$ was used for detection of MDC staining. In order to curtail fluorescent dye quenching, all procedures were performed in a dark room.

\section{Transmission electron microscopy}

After a 24 hour exposure to ESE-16 and the relative controls, cells were collected via trypsinization and fixed in diluted Karnovsky's fixative (2.5\% glutaraldehyde and $2.5 \%$ formaldehyde in $0.075 \mathrm{M}$ phosphate buffer at $\mathrm{pH}$ 7.4-7.6) for 45 minutes at room temperature. Cells were washed with $0.075 \mathrm{M}$ phosphate buffer. Cells were fixed in $0.5 \%$ aqueous osmium for two hours, followed by a rinsing step with distilled water. Dehydration steps followed and entailed increasing concentrations of ethanol (30\%, 50\%, 70\%, 90\%, 100\%, 100\%, 100\%). Cells were infiltrated with a series of increasing percentage of quetol epoxy resin (30\% for 30 minutes, $60 \%$ for 30 minutes and $100 \%$ quetol for four hours). Embedding of samples followed and polymerization of the specimens was allowed for 36 hours at $60^{\circ} \mathrm{C}$. Ultra-thin sections were then prepared with a microtome and mounted on a copper grid. Samples were contrasted with $4 \%$ aqueous uranyl acetate and Reynolds' lead citrate. All chemical were obtained from Merck (Darmstadt, Germany). Samples were viewed with a JEM-210 ${ }^{\circ} \mathrm{F}$ field emission transmission electron microscope (JEOL, Tokyo, Japan) at the Laboratory for Microscopy and Microanalysis, University of Pretoria (Pretoria, South Africa).

\section{Confocal microscopy}

Exponentially growing HeLa cells were seeded at 350000 cells per well in 6-well plates on flame-sterilized cover slips. After exposure, cells on cover slips were washed with prewarmed cytoskeletal buffer (CB) $(60 \mathrm{mM}$ PIPES, $27 \mathrm{mM}$, $10 \mathrm{mM}$ EGTA and $4 \mathrm{mM}$ magnesium sulphate with the 
$\mathrm{pH}$ adjusted to 7.0 with $\mathrm{NaOH})$. Fixation of cells was done with in pre-warmed $0.3 \%$ gluteraldehyde for 10 minutes at $37^{\circ} \mathrm{C}$. This was followed by a wash step with warmed cytoskeletal buffer while agitating. Cell membranes were permeablized using the permeabilization buffer (1\% Triton X-100 in CB) and agitated for 15 minutes. Cells were washed once with $\mathrm{CB}$ buffer and then washed twice with phosphate-buffered saline (PBS). Non-reacting aldehydes were removed by treating samples three times with the reducing agent (5 mg sodium borohydrite in $5 \mathrm{ml} \mathrm{PBS}$ ). Cover slips were incubated in a $10 \%$ normal host serumblocking buffer (10\% FCS in PBS containing 0.05\% Triton $\mathrm{X}-100$ ) for 60 minutes. Cover slips were incubated in a primary mouse anti-tubulin alpha antibody (monoclonal Antibody to Tubulin-alpha (clone DM1A), Imgenex, San Diego, California, USA) cocktail (1:100 ratio antibody to PBS-Triton wash buffer diluted with 50\% blocking buffer) for 90 minutes at $37^{\circ} \mathrm{C}$ in a humidity chamber. Cover slips were washed at room temperature with PBS-Triton wash buffer (PBS with $0.05 \%$ Triton X-100) with 1\% FCS. Samples were incubated while protected from light for 90 minutes at $37^{\circ} \mathrm{C}$ after adding secondary fluorescent labelled (alexa Fluor 488 dye) anti-mouse antibodies (raised in donkey) (Invitrogen, Paisley, United Kingdom) cocktail (1:125 as above) with a final concentration $2 \mathrm{mg} / \mathrm{ml}$. Samples were washed with PBS-Triton wash buffer with FCS. Nuclear staining was achieved by incubating the cover slips in 50\% DAPI (Thermo Fisher Scientific Inc. Rockford, Illinois, USA) to equal volumes of PBS for five to ten minutes while protected from light. Counterstained cover slips were then washed with distilled water, mounted with a glycerol-based mounting fluid and cells were examined with a Zeiss LSM 510 Meta Confocal Microscope (Zeiss, Jena, Germany) at the Laboratory for Microscopy and Microanalysis, University of Pretoria, Pretoria, South Africa. Cells were visualized using immunofluorescent techniques in which green emissions from the Alexa-488 probe were collected at $519 \mathrm{~nm}$ (excited at $495 \mathrm{~nm}$ ) and the blue DAPI at $461 \mathrm{~nm}$ (excited at $358 \mathrm{~nm}$ ).

\section{Statistical analysis}

Quantitative data were obtained from three independent experiments. In addition, each of the independent experiments was conducted in three replicates and is shown as the mean \pm standard deviation (SD). Quantitative data were statistically analyzed for significance using the analysis of variance (ANOVA)-single factor model followed by a two-tailed Student's $t$-test. Means are presented in bar charts, with T-bars referring to standard deviations. $P$-values of less than 0.05 were regarded as statistically significant and are indicated by an asterisk $(*)$. For flow cytometry, three independent experiments were done in triplicate and data from at least 10000 cells were analyzed using Cyflogic version 1.2.1 software (Pertu Therho, Turko, Finland). Flow cytometric measurement of cell cycle progression and protocols involving FITC-labels and the aggresome kit are expressed as relative fluorescence (a percentage of the value measured for vehicle-treated negative control cells). Morphological microscopy studies (qualitative data) were repeated three times.

\section{Additional file}

Additional file 1: Dose response curve: Cytotoxicity determination.

\section{Abbreviations}

2-ME: 2-methoxyestradiol; ESE-16: 2-ethyl-3-O-sulphamoyl-estra-1,3,5(10)16tetraene; CA: carbonic anhydrase; DMSO: Dimethyl sulfoxide; Act D: Actinomycin D; PI3KC3: phosphatidylinositol 3-kinase Catalytic Subunit Type 3; BCL2: B-cell lymphoma 2; TRAIL: tumor necrosis factor (TNF)-related apoptosis-inducing ligand; MDC: monodansylcadaverine.

\section{Competing interests}

The authors declare no competing interests.

\section{Authors' contributions}

AT, EN, LL and AJ were involved in the concept and design, analysis and interpretation of the data and drafting of the manuscript. AT and EN performed all the experiments and acquired the data. All authors read and approved the final manuscript.

\section{Acknowledgments}

Professor D van Papendorp for general support. A Hall and C van der Merwe (Laboratory for Microscopy and Microanalysis, University of Pretoria (UP)), A Stander, D Crafford and S Marais (Department of Physiology, UP) for technical assistance. Ms B English (UP: Research) for editing the manuscript. Dr S Olorunjo (MRC) for statistics consultation. Funding of this research is gratefully acknowledged from the following: The Cancer Association of South Africa (CANCA) (AOS201), the Medical Research Council (MRC) (AOS536), the National Research Foundation (NRF) (AOT060), The Research Committee of the University of Pretoria (RESCOM) (AOR984), South African Medical Association (SAMA) and the Research Development Programme (UP) (AOV8410).

\section{Author details}

${ }^{1}$ Department of Physiology, Faculty of Health Sciences, University of Pretoria, Private Bag X323, Arcadia, 0007 Gauteng, Pretoria, South Africa. ${ }^{2}$ Department of Cellular Differentiation and Transformation, Team\# 03: Polarity,

Development and Cancer, Université Joseph Fourier, Albert Bonniot Institute, CRI INSERM/UJF U823, Grenoble, France.

Received: 16 May 2013 Accepted: 23 August 2013

Published: 27 August 2013

\section{References}

1. Matei D, Schilder J, Sutton G, Perkins S, Breen T, Quon C, Sidor C: Activity of 2 methoxyestradiol (Panzem NCD) in advanced, platinum-resistant ovarian cancer and primary peritoneal carcinomatosis: a Hoosier Oncology Group trial. Gynecol Oncol 2009, 115(1):90-96.

2. Mooberry SL: Mechanism of action of 2-methoxyestradiol: new developments. Drug Resist Update 2003, 6(6):355-361.

3. Tevaarwerk AJ, Holen KD, Alberti DB, Sidor C, Arnott J, Quon C, Wilding G, Liu G: Phase I trial of 2-methoxyestradiol Nano crystal dispersion in advanced solid malignancies. Clin Cancer Res 2009, 15(4):1460-1465.

4. Dubey RK, Jackson EK: Potential vascular actions of 2-methoxyestradiol. Trends Endocrinol Metab 2009, 20(8):374-379.

5. Kato S, Sadarangani A, Lange S, Delpiano AM, Vargas M, Brañes J, Carvajal J, Lipkowitz S, Owen Gl, Cuello MA: 2-Methoxyestradiol mediates apoptosis 
through caspase-dependent and independent mechanisms in ovarian cancer cells but not in normal counterparts. Reprod Sci 2008, 15(9):878-894.

6. Stander BA, Marais S, Vorster CJ, Joubert AM: In vitro effects of 2-methoxyestradiol on morphology, cell cycle progression, cell death and gene expression changes in the tumorigenic MCF-7 breast epithelial cell line. J Steroid Biochem Mol Biol 2010, 119(3-5):149-160.

7. Amorino GP, Freeman ML, Choy H: Enhancement of radiation effects in vitro by the estrogen metabolite 2-methoxyestradiol. Radiat Res 2000, 153(4):384-391.

8. Han G-Z, Liu Z-J, Shimoi K, Zhu BT: Synergism between the anticancer actions of 2-methoxyestradiol and microtubule-disrupting agents in human breast cancer. Cancer Res 2005, 65(2):387-393.

9. Van Zijl C, Lottering ML, Steffens F, Joubert A: In vitro effects of 2-methoxyestradiol on MCF-12A and MCF-7 cell growth, morphology and mitotic spindle formation. Cell Biochem Funct 2008, 26(5):632-642.

10. Fotsis T, Zhang Y, Pepper MS, Adlercreutz H, Montesano R, Nawroth PP, Schweigerer $\mathrm{L}$ : The endogenous oestrogen metabolite 2-methoxyoestradiol inhibits angiogenesis and suppresses tumour growth. Nature 1994, 368(6468):237-239

11. Newman SP, Ireson CR, Tutill HJ, Day JM, Parsons MFC, Leese MP, Potter BVL, Reed MJ, Purohit A: The role of $17 \beta$-hydroxysteroid dehydrogenases in modulating the activity of 2-methoxyestradiol in breast cancer cells. Cancer Res 2006, 66(1):324-330.

12. Sweeney C, Liu G, Yiannoutsos C, Kolesar J, Horvath D, Staab MJ, Fife K, Armstrong $\mathrm{V}$, Treston A, Sidor C, et al: A phase II multicenter, randomized, double-blind, safety trial assessing the pharmacokinetics, pharmacodynamics, and efficacy of oral 2-methoxyestradiol capsules in hormone-refractory prostate cancer. Clin Cancer Res 2005, 11(18):6625-6633.

13. Tsuchiya Y, Nakajima M, Yokoi T: Cytochrome P450-mediated metabolism of estrogens and its regulation in human. Cancer Lett 2005, 227(2):115-124.

14. Du B, Li Y, Li X, AY, Chen C, Zhang Z: Preparation, characterization and in vivo evaluation of 2-methoxyestradiol-loaded liposomes. Int J Pharm 2010, 384(1-2):140-147.

15. Visagie MH, Joubert AM: In vitro effects of 2-methoxyestradiol-bis-sulphamate on reactive oxygen species and possible apoptosis induction in a breast adenocarcinoma cell line. Cancer Cell Int 2011, 11(1):43.

16. Pasquier E, Sinnappan S, Munoz MA, Kavallaris M: ENMD-1198, a New Analogue of 2-Methoxyestradiol, Displays Both Antiangiogenic and Vascular-Disrupting Properties. Mol Cancer Ther 2010, 9(5):1408-1418.

17. Stander XX, Stander BA, Joubert AM: In vitro effects of an in silico-modelled $17 \beta$-estradiol derivative in combination with dichloroacetic acid on MCF-7 and MCF-12A cells. Cell Prolif 2011, 44(6):567-581.

18. Marais S, Mqoco T, Stander A, van Papendorp D, Joubert $A$ : The in vitro effects of a sulphamoylated derivative of 2-methoxyestradiol on cell number, morphology and alpha-Tubulin disruption in cervical adenocarcinoma (HeLa) cells. Biomed Res 2012, 23(3):357-362.

19. Tinley TL, Leal RM, Randall-Hlubek DA, Cessac JW, Wilkens LR, Rao PN, Mooberry SL: Novel 2-methoxyestradiol analogues with antitumor activity. Cancer Res 2003, 63(7):1538-1549.

20. Cushman M, He HM, Katzenellenbogen JA, Lin CM, Hamel E: Synthesis, anti-Tubulin and anti-mitotic activity, and cytotoxicity of analogs of 2-methoxyestradiol, an endogenous mammalian metabolite of Estradiol that inhibits Tubulin polymerization by binding to the colchicine binding site. J Med Chem 1995, 38(12):2041-2049.

21. Leese MP, Newman SP, Purohit A, Reed MJ, Potter BV: 2-Alkylsulfanyl estrogen derivatives: synthesis of a novel class of multi-targeted antitumour agents. Bioorg Med Chem Lett 2004, 14(12):3135-3138.

22. LaVallee TM, Burke PA, Swartz GM, Hamel E, Agoston GE, Shah J, Suwandi L, Hanson AD, Fogler WE, Sidor CF, et al: Significant antitumor activity in vivo following treatment with the microtubule agent ENMD-1198. Mol Cancer Ther 2008, 7(6):1472-1482.

23. Edsall AB, Mohanakrishnan AK, Yang D, Fanwick PE, Hamel E, Hanson AD, Agoston GE, Cushman M: Effects of altering the electronics of 2-methoxyestradiol on cell proliferation, on cytotoxicity in human cancer cell cultures, and on Tubulin polymerization. J Med Chem 2004, 47(21):5126-5139.

24. Elger W, Schwarz S, Hedden A, Reddersen G, Schneider B: Sulfamates of various estrogens are pro-drugs with increased systemic and reduced hepatic estrogenicity at oral application. J Steroid Biochem Mol Biol 1995 55(3-4):395-403.

25. Ho YT, Purohit A, Vicker N, Newman SP, Robinson JJ, Leese MP, Ganeshapillai D, Woo LWL, Potter BVL, Reed MJ: Inhibition of carbonic anhydrase II by steroidal and non-steroidal sulphamates. Biochem Biophys Res Commun 2003, 305(4):909-914.

26. Pastorekova S, Ratcliffe PJ, Pastorek J: Molecular mechanisms of carbonic anhydrase IX-mediated $\mathrm{pH}$ regulation under hypoxia. BJU Int 2008, 101(Suppl 4):8-15.

27. Chiche J, Ilc K, Laferrière J, Trottier E, Dayan F, Mazure NM, Brahimi-Horn MC, Pouysségur J: Hypoxia-inducible carbonic anhydrase IX and XII promote tumor cell growth by counteracting acidosis through the regulation of the intracellular $\mathrm{pH}$. Cancer Res 2009, 69(1):358-368.

28. Stubbs M, McSheehy PM, Griffiths JR, Bashford CL: Causes and consequences of tumour acidity and implications for treatment. Mol Med Today 2000, 6(1):15-19.

29. Leese MP, Leblond B, Smith A, Newman SP, Di Fiore A, De Simone G, Supuran CT, Purohit A, Reed MJ, Potter BV: 2-substituted Estradiol bis-sulfamates, multitargeted antitumor agents: synthesis, in vitro SAR, protein crystallography, and in vivo activity. J Med Chem 2006, 49(26):7683-7696.

30. Elger W, Barth A, Hedden A, Reddersen G, Ritter P, Schneider B, Züchner J, Krahl E, Müller K, Oettel M, Schwarz S: Estrogen sulfamates: a new approach to oral estrogen therapy. Reprod Fertil Dev 2001, 13(4):297-305.

31. Vorster C, Joubert A: In vitro effects of 2-methoxyestradiol-bis-sulphamate on cell growth, morphology and cell cycle dynamics in the MCF-7 breast adenocarcinoma cell line. Biocell 2010, 34(2):71-79.

32. Ireson CR, Chander SK, Purohit A, Perera S, Newman SP, Parish D, Leese MP, Smith AC, Potter BV, Reed MJ: Pharmacokinetics and efficacy of 2-methoxyoestradiol and 2-methoxyoestradiol-bis-sulphamate in vivo in rodents. Br J Cancer 2004, 90(4):932-937.

33. Stander A, Joubert F, Joubert A: Docking, synthesis, and in vitro evaluation of antimitotic Estrone analogs. Chem Biol Drug Des 2011, 77(3):173-181

34. Miyazaki T, Arai S: Two distinct controls of mitotic Cdk1/Cyclin B1 activity requisite for cell growth prior to cell division. Cell Cycle 2007, 6(12):1418-1424.

35. Boucrot E, Kirchhausen T: Mammalian cells change volume during mitosis. PLOS ONE 2008, 3(1):e1477.

36. Laane E, Tamm KP, Buentke E, Ito K, Khahariza P, Oscarsson J, Corcoran M, Bjorklund AC, Hultenby K, Lundin J, et al: Cell death induced by Dexamethasone in lymphoid leukemia is mediated through initiation of autophagy. Cell Death Differ 2009, 16(7):1018-1029.

37. Thaver $\mathrm{V}$, Lottering $M L$, van Papendorp $D$, Joubert $A$ : In vitro effects of 2-methoxyestradiol on cell numbers, morphology, cell cycle progression, and apoptosis induction in oesophageal carcinoma cells. Cell Biochem Funct 2009, 27(4):205-210.

38. Li L, Bu S, Backstrom T, Landstrom M, Ulmsten U, Fu X: Induction of apoptosis and G2/M arrest by 2-methoxyestradiol in human cervical cancer HeLaS3 cells. Anticancer Res 2004, 24(2B):873-880.

39. Androic I, Kramer A, Yan R, Rodel F, Gatje R, Kaufmann M, Strebhardt K, Yuan J: Targeting cyclin B1 inhibits proliferation and sensitizes breast cancer cells to taxol. BMC Cancer 2008, 8(1):391.

40. Matson DR, Stukenberg PT: Spindle poisons and cell fate: a tale of two pathways. Mol Interv 2011, 11(2):141-150.

41. Wertz IE, Kusam S, Lam C, Okamoto T, Sandoval W, Anderson DJ, Helgason E, Ernst JA, Eby M, Liu J, et al: Sensitivity to anti-Tubulin chemotherapeutics is regulated by MCL1 and FBW7. Nature 2011, 471(7336):110-114

42. Newman SP, Foster PA, Stengel C, Day JM, Ho YT, Judde J-G, Lassalle M, Prevost G, Leese MP, Potter BVL, et al: STX140 is efficacious in vitro and in vivo in taxane-resistant breast carcinoma cells. Clin Cancer Res 2008 14(2):597-606.

43. Huang H-C, Shi J, Orth JD, Mitchison TJ: Evidence that mitotic exit is a better cancer therapeutic target than spindle assembly. Cancer Cell 2009, 16(4):347-358

44. LaVallee TM, Zhan XH, Johnson MS, Herbstritt CJ, Swartz G, Williams MS, Hembrough WA, Green SJ, Pribluda VS: 2-methoxyestradiol up-regulates death receptor 5 and induces apoptosis through activation of the extrinsic pathway. Cancer Res 2003, 63(2):468-475.

45. Ola M, Nawaz M, Ahsan H: Role of Bcl-2 family proteins and caspases in the regulation of apoptosis. Mol Cell Biochem 2011, 351(1):41-58.

46. Kadowaki M, Karim MR, Carpi A, Miotto G: Nutrient control of macro-autophagy in mammalian cells. Mol Aspects Med 2006, 27(5-6):426-443.

47. Djavaheri-Mergny M, Maiuri MC, Kroemer G: Cross talk between apoptosis and autophagy by caspase-mediated cleavage of Beclin 1.

Oncogene 2010, 29(12):1717-1719. 
48. Maiuri MC, Zalckvar E, Kimchi A, Kroemer G: Self-eating and self-killing: crosstalk between autophagy and apoptosis. Nat Rev Mol Cell Biol 2007, 8(9):741-752.

49. Xie Z, Klionsky DJ: Autophagosome formation: core machinery and adaptations. Nat Cell Biol 2007, 9(10):1102-1109.

50. Wirawan E, Vande Walle L, Kersse K, Cornelis S, Claerhout S, Vanoverberghe I, Roelandt R, De Rycke R, Verspurten J, Declercq W, et al: Caspase-mediated cleavage of Beclin-1 inactivates Beclin-1-induced autophagy and enhances apoptosis by promoting the release of proapoptotic factors from mitochondria. Cell Death Dis 2010, 1(1):e18.

51. Cho DH, Jo YK, Hwang JJ, Lee YM, Roh SA, Kim JC: Caspase-mediated cleavage of ATG6/Beclin-1 links apoptosis to autophagy in HeLa cells. Cancer Lett 2009, 274(1):95-100.

52. Luo S, Rubinsztein DC: Apoptosis blocks Beclin 1-dependent autophagosome synthesis: an effect rescued by Bcl-xL. Cell Death Differ 2010, 17(2):268-277.

53. Betin VMS, Lane JD: Caspase cleavage of Atg4D stimulates GABARAP-L1 processing and triggers mitochondrial targeting and apoptosis. J Cell SCi 2009, 122(14):2554-2566.

doi:10.1186/1475-2867-13-87

Cite this article as: Theron et al: Molecular crosstalk between apoptosis and autophagy induced by a novel 2-methoxyestradiol analogue in cervical adenocarcinoma cells. Cancer Cell International 2013 13:87.

\section{Submit your next manuscript to BioMed Central and take full advantage of:}

- Convenient online submission

- Thorough peer review

- No space constraints or color figure charges

- Immediate publication on acceptance

- Inclusion in PubMed, CAS, Scopus and Google Scholar

- Research which is freely available for redistribution 